\title{
Towards Noble-Metal-Free Dyads: Ground and Excited State Tuning by a Cobalt Dimethylglyoxime Motif Connected to an Iron N-Heterocyclic Carbene Photosensitizer
}

Zimmer, Peter; Burkhardt, Lukas; Schepper, Rahel; Zheng, Kaibo; Gosztola, David; Neuba, Adam; Flörke, Ulrich; Wölper, Christoph; Schoch, Roland; Gawelda, Wojciech

Total number of authors:

12

Published in:

European Journal of Inorganic Chemistry

Link to article, DOI:

10.1002/ejic.201800946

Publication date:

2018

Document Version

Peer reviewed version

Link back to DTU Orbit

Citation (APA):

Zimmer, P., Burkhardt, L., Schepper, R., Zheng, K., Gosztola, D., Neuba, A., Flörke, U., Wölper, C., Schoch, R., Gawelda, W., Canton, S. E., \& Bauer, M. (2018). Towards Noble-Metal-Free Dyads: Ground and Excited State Tuning by a Cobalt Dimethylglyoxime Motif Connected to an Iron N-Heterocyclic Carbene Photosensitizer. European Journal of Inorganic Chemistry, 2018(48), 5203-5214. https://doi.org/10.1002/ejic.201800946

\section{General rights}

Copyright and moral rights for the publications made accessible in the public portal are retained by the authors and/or other copyright owners and it is a condition of accessing publications that users recognise and abide by the legal requirements associated with these rights.

- Users may download and print one copy of any publication from the public portal for the purpose of private study or research.

- You may not further distribute the material or use it for any profit-making activity or commercial gain

- You may freely distribute the URL identifying the publication in the public portal 


\section{EurJll \\ European Journal of Inorganic Chemistry}

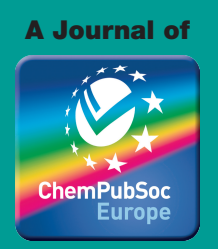

\section{Accepted Article}

Title: Towards noble-metal free dyads: Ground and excited state tuning by a cobalt dimethylglyoxime catalyst connected to an iron $\mathrm{N}$ heterocyclic carbene photosensitizer

Authors: Peter Zimmer, Lukas Burkhardt, Rahel Schepper, David Gosztola, Kaibo Zheng, Adam Neuba, Ulrich Flörke, Christoph Wölper, Roland Schoch, Wojciech Gawelda, Sophie E. Canton, and Matthias Bauer

This manuscript has been accepted after peer review and appears as an Accepted Article online prior to editing, proofing, and formal publication of the final Version of Record (VoR). This work is currently citable by using the Digital Object Identifier (DOI) given below. The VoR will be published online in Early View as soon as possible and may be different to this Accepted Article as a result of editing. Readers should obtain the VoR from the journal website shown below when it is published to ensure accuracy of information. The authors are responsible for the content of this Accepted Article.

To be cited as: Eur. J. Inorg. Chem. 10.1002/ejic.201800946

Link to VoR: http://dx.doi.org/10.1002/ejic.201800946 


\title{
Towards noble-metal free dyads: Ground and excited state tuning by a cobalt dimethylglyoxime motif connected to an iron $\mathbf{N}$-heterocyclic carbene photosensitizer
}

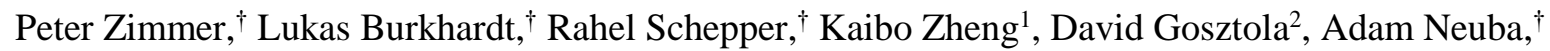
Ulrich Flörke, ${ }^{\dagger}$ Christoph Wölper, ${ }^{3}$ Roland Schoch,${ }^{\dagger}$ Wojciech Gawelda ${ }^{4}$, Sophie E. Canton ${ }^{\$ *}$, Matthias Bauer**

${ }^{\dagger}$ P. Zimmer, L. Burkhardt, R. Schepper, Dr. A. Neuba, Dr. U. Flörke, Dr. R. Schoch, Prof. Dr. M. Bauer, Faculty of science, Paderborn University, Warburger Straße 100, 33098 Paderborn, Germany

E-mail: matthias.bauer@upb.de, https://chemie.uni-paderborn.de/en/arbeitskreise/anorganische-undanalytische-chemie/bauer/

${ }^{\$}$ Dr. S. E. Canton, ELI-ALPS, ELI-HU Non-Profit Ltd., Dugonics ter 13, Szeged 6720, Hungary \&

Attosecond Science Group, Deutsches Elektronen-Synchrotron (DESY), Notkestrasse 85, D-22607

Hamburg, Germany

E-mail: sophie.canton@desy.de,

1) Dr. Kaibo Zheng, Department of Chemistry, Technical University of Denmark, DK-2800 Kongens

Lyngby, Denmark

\& Department of Chemical Physics and NanoLund, Lund University, Box 124, 22100, Lund, Sweden

2) Dr. D. Gosztola, Center for Nanoscale Materials, Argonne National Laboratory, 9700 S. Cass

Avenue, Lemont, Illinois 60439, United States

3) Dr. C. Wölper, Institute for Inorganic Chemistry and Center for Nanointegration Duisburg-Essen

(Cenide), University of Duisburg-Essen, Universitätsstraße 5-7, D-45117 Essen, Germany

4) Dr. W. Gawelda, European XFEL, Holzkoppel 4, 22869 Schenefeld, Germany

\& Faculty of Physics, Adam Mickiewicz University, Umultowska 85, 61-614 Poznań, Poland

\begin{abstract}
Heteroleptic iron based complexes bearing the 2,6-bis[3-(2,6-diisopropylphenyl)imidazol-2ylidene]pyridine motif and a polypridine ligand have been synthesized and characterized in their ground and excited state. This series of complexes includes a first example of a hetero-bimetallic complex connecting an iron $\mathrm{N}$-heterocyclic carbene photosensitizer with a cobalt dimethylglyoxime fragment. Focus is set on the influence of the linker and cobalt center as second ligand at the iron center on the photophysics. While electronic absorption spectroscopy and cyclic voltammetry reveal a weak mutual influence of the single ligands in the heteroleptic complexes, an increasing MLCT lifetime with larger $\pi$-accepting abilities was found by time-resolved transient absorption spectroscopy, with maximum lifetime in the case of the hetero-bimetallic dyad. Concurrently the MC lifetimes were observed to decrease. The reported results will allow to develop guidelines for designing bimetallic devices, which may allow electron transfer from the photosensitizer fragment to a catalytically active center.
\end{abstract}

\section{Introduction}

Realizing photocatalytic proton reduction as partial reaction of the complete sun-driven water splitting process is crucial to allow sustainable production of hydrogen. So far, numerous model systems based on ruthenium ${ }^{[1,2]}$ or iridium photosensitizers ${ }^{[3]}$ in combination with catalysts containing platinum ${ }^{[2,4]}$, cobalt $^{[5,6]}$ or iron ${ }^{[7]}$ have been employed. A definite disadvantage of such systems is the use of noble metals in the active photosensitizing and catalyst components, associated to unfavorable economic and ecological reasons. Over the last several years, non-noble photosensitizers and proton reduction catalysts have been placed in scientific focus.

Iron is considered as a sustainable and earth-abundant element. However, iron complexes are characterized by comparatively low ligand field splitting, which results in energetically low-lying metal centered (MC) states. ${ }^{[8-13,14,15-17]}$ As a consequence, the metal-to-ligand charge-transfer states (MLCT) are short-lived with fast non-radiative deactivation pathways into relatively long-living MC states. Recent work focuses on the increase of MLCT lifetimes by application of strong donor ligands, with a particular interest in $N$-heterocyclic carbenes. ${ }^{[13,17]}$ Considerable success has been achieved using this 
strategy. ${ }^{[10,11]}$ However, the so far reported lifetimes are still in the picosecond (ps) range, and thus comparatively short. Direct electron transfer via bridging ligands in bimetallic complexes, the so-called dyads, is a potential approach to utilize such rather short lifetimes in proton reduction reactions, since diffusion-controlled and thus ineffective charge transfer can be circumvented. However, so far little has been reported about the effect of covalently linking a second hetero-metallic complex and the resulting photophysics of such iron chromophores are not yet available.

In this work, we present the first $\mathrm{Fe}-\mathrm{Co}$ dyad, connecting a heteroleptic $\mathrm{Fe}(\mathrm{II})-\mathrm{NHC}$ photosensitizer motif ${ }^{[13,18,19]}$ via a polypyridyl linker to a Co(III) dimethylglyoxime. ${ }^{[20]} \mathrm{We}$ focus on the influence of the linker and cobalt center on the early steps of the underlying photophysical process at the iron center. Although the studied hetero-metallic compound is not likely to be catalytically active due to the rapid iron-based excited state relaxation, the results are proof of the concept that a covalently linked second metal can be employed to optimize the photophysics of such systems.

\section{Results}

Based on our previously published heteroleptic complex bearing a tridentate bis-NHC ligand and a terpy (terpy $=2,2^{\prime}: 6^{\prime}, 2^{\prime \prime}$-terpyridine) ligand, ${ }^{[19]}$ the related complex $[\mathrm{FeL} 1$ (pyterpy) $]\left[\mathrm{PF}_{6}\right]_{2} \mathbf{1}$ was synthesized (pyterpy $=\mathrm{L} 2=4^{\prime}-\left(4^{\prime \prime \prime}\right.$-pyridyl)-2,2':6',2"-terpyridine; L1 =2,6-bis[3-(2,6diisopropylphenyl)imidazol-2-ylidene]pyridine) in order to utilize the fact that the electronic nature of the substituents attached to the $4^{\prime}$ position of terpy allows significant control over the photophysical properties. ${ }^{[21]}$ By employing 4-pyridyl, pendant-functionalization by protonation, ${ }^{[18]}$ methylation ${ }^{[22,23]}$ or coordination of metal fragments ${ }^{[24]}$ allow multiple applications. Based on 1, the synthesis and structure of a new bimetallic complex 3 shown in scheme 1, which connects an iron(II) center and a chlorobis(dimethylglyoximato)cobalt(III) motif, is presented (dimethylglyoximato $=\mathrm{dmgH}$ ). For comparison, the $N$-methylated complex 2 was also prepared. Such systems can be described as metalcontaining topographical analogues of $N, N$-Dialkyl-4,4-bipyridinium salts (see orange colored fragments in scheme 1). ${ }^{[23]}$ These salts, also known as viologens, are electron transfer reagents in many photochemical applications due to their reversible reduction properties. ${ }^{[25]}$ To the best of our knowledge, 3 is the first example of a bimetallic complex connecting a NHC-ligand based iron(II) complex with a cobalt(III) dmgH motif. The former are promising candidates for iron-based photosensitizers ${ }^{[9]}$ the latter are known to be effective catalysts in photocatalytic water reduction processes. ${ }^{[6,26]}$ Thorough characterization by means of absorption spectroscopy, Valence-to-Core X-ray emission spectroscopy (VtC-XES), High Resolution Fluorescence Detected X-ray Absorption Near Edge Structure (HERFDXANES), cyclic voltammetry (CV) and transient optical absorption spectroscopy give insights into the ground and excited state properties in order to pave the way to future photocatalytic applications. 

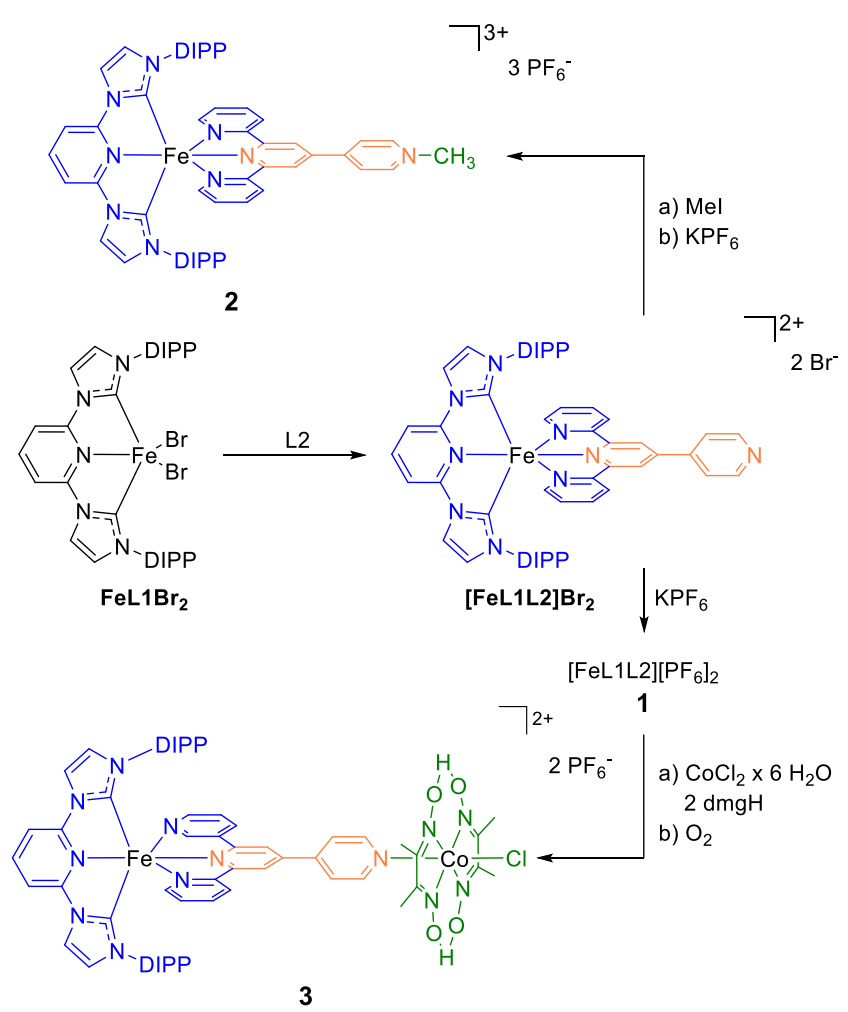

Scheme 1. Route of synthesis for complexes 1-3. The viologen motif is marked in orange (DIPP = 2,6diisopropylphenyl).

The synthesis of $\mathbf{1}$ is based on a recently published protocol. ${ }^{[19]}$ It starts with the well-known fivecoordinated iron precursor FeL1(Br) 2 (A, scheme 1). ${ }^{[27]}$ Subsequent substitution of the bromide ligands by the polypyridyl ligand L2 results in the six-coordinated complex $[\mathrm{Fe}(\mathrm{L} 1)(\mathrm{L} 2)] \mathrm{Br}_{2}$ (B) with $52 \%$ yield. Complex $\mathbf{1}$ is obtained by nearly quantitative anion exchange with $\mathrm{KPF}_{6}$ in water. Note, that $\mathbf{1}$ is similar to an already published complex by Duchanois et al ${ }^{[18]}$ However, the synthesis route directly starts with iron(II) and therefore affords higher yields. ${ }^{[19]}$ By direct methylation of $[\mathrm{Fe}(\mathrm{L} 1)(\mathrm{L} 2)] \mathrm{Br}_{2}$ with methyl iodide in acetonitrile, followed by an anion exchange complex 2 is isolated with $77 \%$ yield. The bimetallic complex 3 and reference $\mathrm{CoCl}(\mathrm{dmgH})_{2}(\mathbf{4})$ were synthesized by a modified protocol of Schrauzer et al... ${ }^{[28]}$ In the case of $\mathbf{3}$, complex $\mathbf{1}$ is directly employed as pyridine source. Subsequent oneelectron oxidation of $\mathrm{Co}(\mathrm{II})$ is occurred by passing $\mathrm{O}_{2}$ through the solution. Finally, crystallization by diffusion of chloroform into an acetone solution yields $60 \%$ of $\mathbf{3}$ as purple colored crystals. Alternatively, the synthesis of $\mathbf{3}$ can also be performed by employing the di-bromido complex B with subsequent anion change by $\left[\mathrm{PF}_{6}\right]^{-}$. Single crystals of $\mathbf{1}$ and $\mathbf{3}$ suitable for X-ray diffraction are then obtained by slow diffusion of chloroform into the acetone solution. $\mathbf{2}$ crystallized by diffusion of diethylether into an acetone solution. The structure of $\mathbf{1}$ is shown in figure 1 . As known for other complexes with ligand L2, ${ }^{[23]}$ the outer pyridine ring of 1 is similarly twisted by $55.3(3)^{\circ}$ with respect to the terpy plane. This may be attributed to adverse steric interactions between the hydrogen atoms in ortho-position to the torsion axis. The L1 and L2 ligands set up a dihedral angle of $89.5(1)^{\circ}$. In the case of 2 , the L1/L2 dihedral angle amounts to $89.7(2)^{\circ}$ (cf. figure 2 ). 


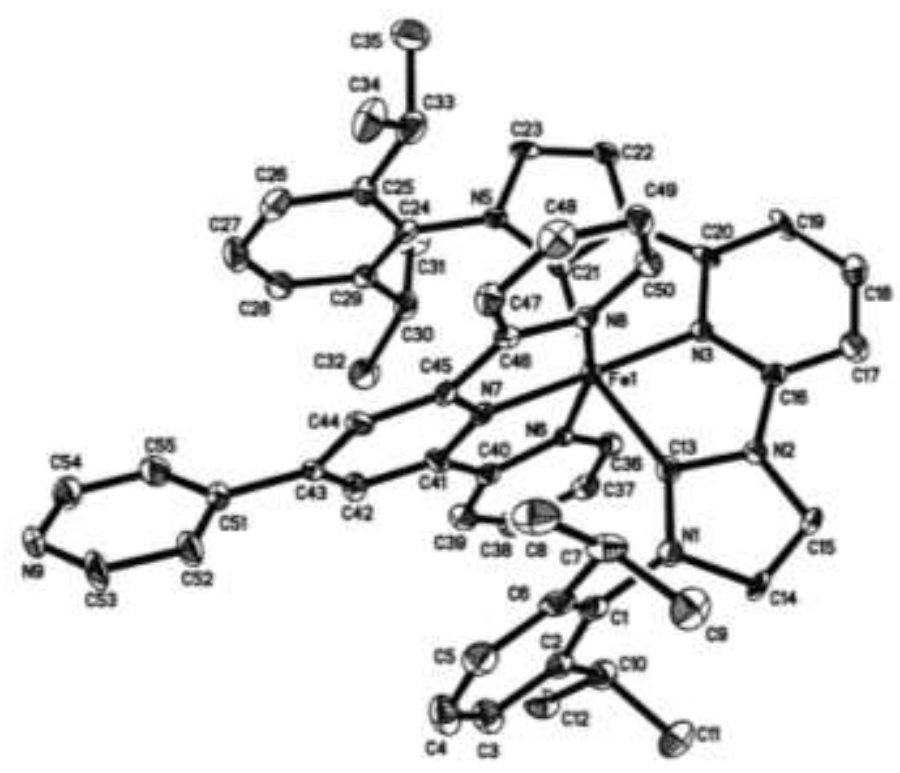

Figure 1. Molecular structure of 1. Hydrogen atoms, anions, and co-crystallized solvent molecules are omitted for clarity. Anisotropic displacement ellipsoids are drawn at the 50\% probability level.

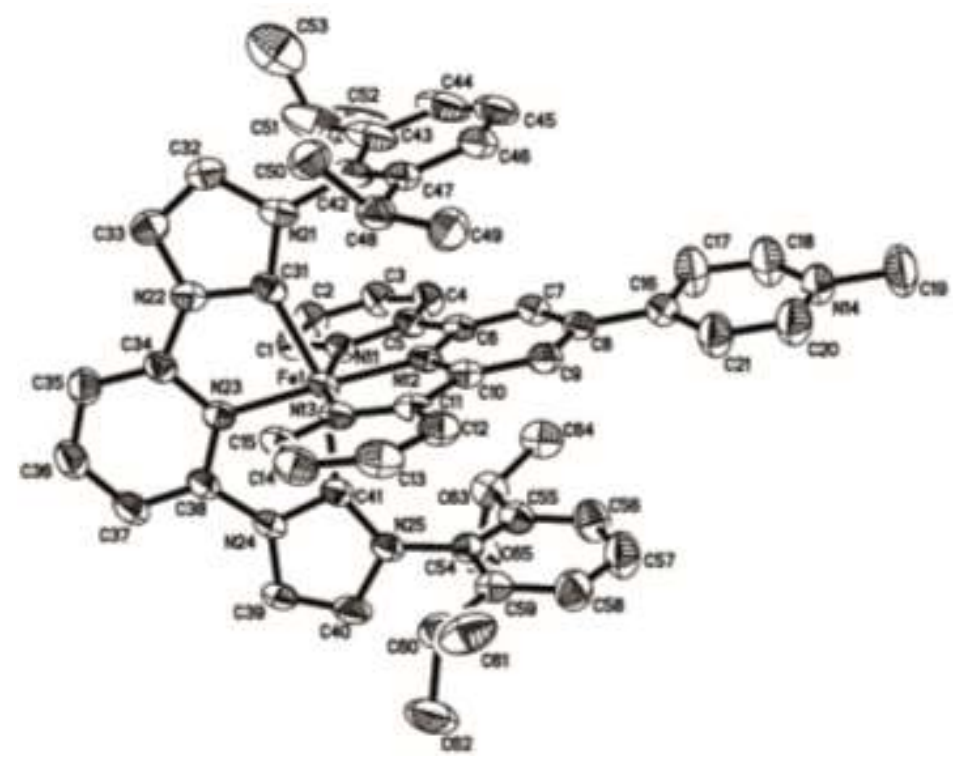

Figure 2. Molecular structure of 2. Hydrogen atoms, anions, and co-crystallized solvent molecules are omitted for clarity. Anisotropic displacement ellipsoids are drawn at the 50\% probability level.

The molecular structure of $\mathbf{3}$ in figure 3 proves the coordination of the Lewis-basic site of $\mathbf{1}$ directly to the cobalt center with a chloro ligand in trans-position. In the equatorial plane, two dimethylglyoxim motifs form the expected planar pseudo-macrocycle. There as well, the typical L2-torsion already discussed for $\mathbf{1}$ is observed with $37.9(2)^{\circ}$ and the L1/L2 dihedral angle amounts to $87.4(2)^{\circ}$. In contrast, L2 in 2 is nearly planar, since the torsion angle measures only 8.2(8) ${ }^{\circ}$ X-ray Absorption Near Edge Structure (XANES) and Extended X-ray Absorption Fine Structure (EXAFS) analysis were performed for complex 3 to extract further information about the geometric and electronic structure at the $\mathrm{Fe}$ and Co center. As expected, the edge positions of $7119.5 \mathrm{eV}$ at the Fe K-edge and of $7719.0 \mathrm{eV}$ at the Co K-edge are consistent with oxidation states of iron(II) and cobalt (III), respectively. ${ }^{[13]}$ For both edges, the obtained structural parameters agree very well with the crystallographic data, underlining the high potential of EXAFS for future in-situ studies (see supporting information for details). 


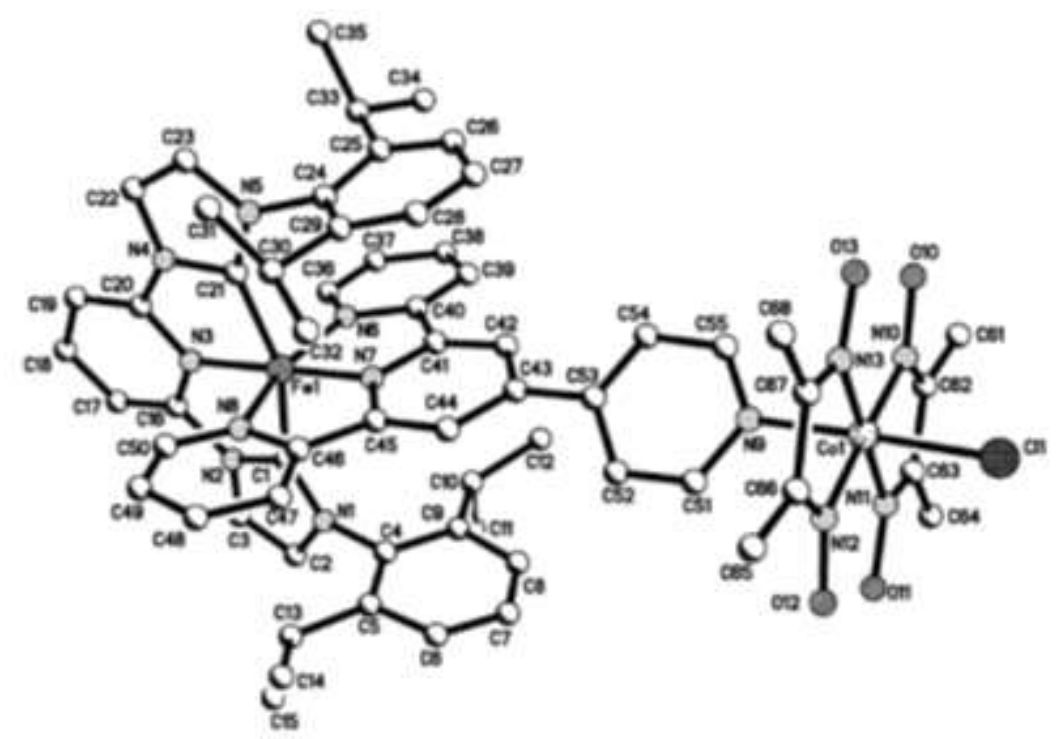

Figure 3. Molecular structure of 3. Hydrogen atoms, anions, and co-crystallized solvent molecules are omitted for clarity.

DFT geometry optimizations of the complexes $\mathbf{1}$ - $\mathbf{3}$ resulted in geometric structures that are in good agreement with the crystallographic structures discussed above (see supporting information). The distances from the metal centers to the coordinating ligand atoms are reported in the Table 1. Comparing the coordination around the $\mathrm{Fe}$ (II) center shows that this moiety is not affected by the coordination to the $\mathrm{Co}(\mathrm{III})$ moiety. In addition, the torsion of the bridging pyridine shows similar values $\left(44-49^{\circ}\right)$ for $\mathbf{1}$ 3. This should prevent extended delocalization of the molecular orbitals into the pendant pyridine ring. Nevertheless, for $\mathbf{3}$ and especially for the pyridine-functionalized complexes $\mathbf{2}$, a significant contribution of the rotated ring to the LUMO was found (see supporting information for details). The torsion of this ring is significantly influenced by packing effects in the crystal structures, since for $\mathbf{1}$ and $\mathbf{3}$ the torsion angles variations are much more pronounced. In contrast, for $\mathbf{2}$ the methylated ligand was found to be nearly planar, which cannot be explained by electronic effects or be reproduced by the DFT-calculations.

Table 1: DFT parameters in comparison to the crystallographic data (in square brackets).

\begin{tabular}{|l|l|l|l|l|}
\hline Bond lengths $[\AA]$ and angles [ $\left.{ }^{\circ}\right]$ & $\mathbf{1}$ & $\mathbf{2}$ & $\mathbf{3}$ & $\mathbf{4}^{[\mathrm{a}]}$ \\
\hline $\mathrm{Fe}^{\mathrm{N}} \mathrm{terpy}_{\text {taxial }}$ & 1.889 & 1.885 & 1.889 & - \\
& {$[1.858(7)]$} & {$[1.844(4)]$} & {$[1.847(8)]$} & \\
\hline $\mathrm{Fe}-\mathrm{N}_{\text {terpy-distal, averaged }}$ & 2.009 & 2.006 & 2.009 & - \\
& {$[1.956]$} & {$[1.970(5)]$} & {$[1.973]$} & \\
\hline $\mathrm{Fe}-\mathrm{N}_{\text {carbene }}$ & 1.945 & 1.948 & 1.945 & - \\
& {$[1.919(7)]$} & {$[1.920(4)]$} & {$[1.900(8)]$} & \\
\hline Fe- $\mathrm{C}_{\text {carbene, averaged }}$ & 2.016 & 2.018 & 2.017 & - \\
\hline $\mathrm{Co}-\mathrm{N}_{\text {dmgH, averaged }}$ & {$[1.982]$} & {$[1.989(6)]$} & {$[1.989]$} & \\
\hline $\mathrm{Co}-\mathrm{N}_{\text {bridge }}$ & - & - & 1.906 & 1.905 \\
& & & {$[1.886]$} & \\
\hline $\mathrm{Co}-\mathrm{Cl}$ & - & - & 2.008 & 2.001 \\
& & & {$[1.961(8)]$} & $1.959(2)$ \\
\hline Torsion & & - & 2.189 & 2.201 \\
& - & {$[2.219(3)]$} & $2.229(1)$ \\
\hline
\end{tabular}

[a] adapted from ref. $2^{[29]}$ 
In order to further prove the oxidation state of $\mathrm{Fe}(\mathrm{II})$ the local spin density of complexes $\mathbf{1}-\mathbf{3}$ was accessed by iron K-egde Core-to-Core X-ray emission spectroscopy (CtC-XES). ${ }^{[30]}$ The spectra are shown in figure S4-1 in the supplementary information. All three complexes exhibit identical spectral shapes, which are characteristic for a low-spin Fe(II) enter. ${ }^{[30]}$

The detection of changes in the HOMO and LUMO levels at the iron centers as a function of the coordinating groups is possible using high energy resolution by VtC-XES and HERFD-XANES. ${ }^{[31]}$ The sensitivity of both methods to the coordination of NHC or pyridyl functions has been discussed in a former study. ${ }^{[13]}$ The occupied levels are probed by VtC-XES, the experimental spectra are shown in Figure S4-2 of the supporting information. In general three VtC-XES features A - C are observed. Feature A is mainly caused by pyridyl / polypyridyl localized donor orbitals, feature B is a superposition of pyridyl and NHC localized donor orbitals and feature $\mathrm{C}$ is solely due to $\mathrm{t}_{2 \mathrm{~g}}$ levels. ${ }^{[13]}$ All three complexes exhibit equal energies and intensities for all experimental observed VtC-XES features, apart from a slight increase in intensity of the main feature B for complex $\mathbf{1}$. Therefore, no significant shifts of $t_{2 g}$ or other HOMO levels are observed. HERFD-XANES spectra of $\mathbf{1}$ - $\mathbf{3}$ are shown in Figure S4-3 in the Supporting Information. In general, two pre-edge features A, B and two near-edge features C and $\mathrm{D}$ are observed. The pre-edge is an effective probe for $\mathrm{e}_{\mathrm{g}}{ }^{*}$ levels, while near edge feature $\mathrm{C}$ is a probe for NHC coordination whereas feature D is a probe for pyridyl / polypyridyl coordination. Similar intensitites of pre-edge and near-edge features A - D (energy and intensity ratios) are found for all three complexes. Consequently, no significant shifts of $\mathrm{e}_{\mathrm{g}}{ }^{*}$ or other LUMO levels are observed. Therefore, modification of the terpyridine framework is expected to mainly influence the LUMO levels of these complexes. DFT calculations reproduce the experimental X-ray spectra quite well (cf. supporting information).

The DFT calculated solvation HOMO and LUMO levels of $\mathbf{1}-\mathbf{3}$ being relevant for the discussion of the subsequent spectroscopic investigations are depicted in Figure 4. For comparison, the calculated energy levels of $\mathbf{4}$ and $\left[\mathrm{Fe}(\mathrm{L} 1)(\right.$ terpy)$]\left[\mathrm{PF}_{6}\right]_{2} \mathbf{5}$ and are also shown.

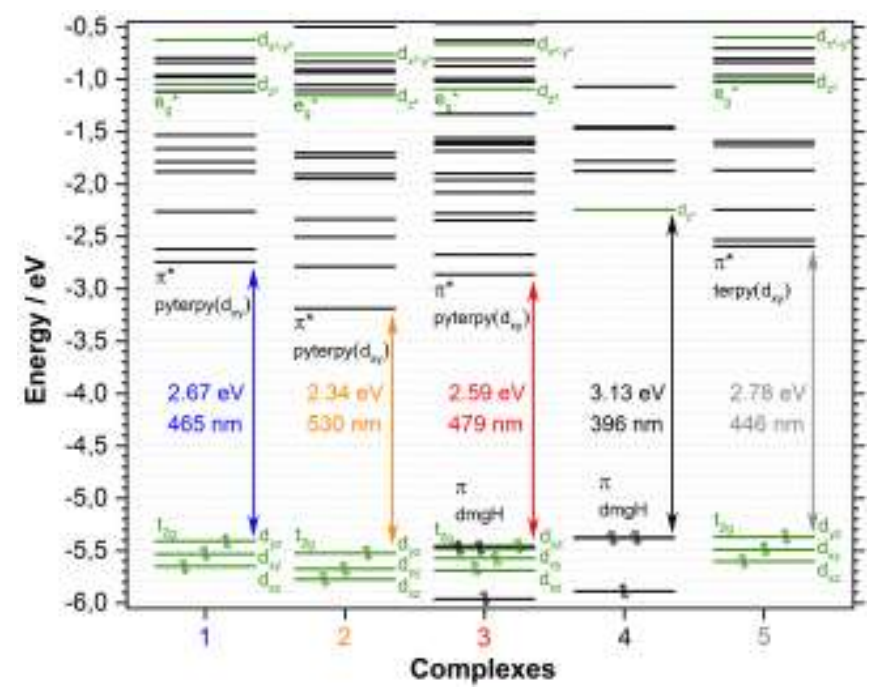

Figure 4. Molecular orbital levels of complexes 1-5 (def2-TZVPP, TPSSh, SMD (acetonitrile), for details see the experimental section). Theoretical HOMO-LUMO gaps are indicated. Levels with significant metal-3d contribution are shown in green. The predominant characters of LUMOs and HOMOs are also specified.

The LUMO levels of $\mathbf{1}$ are stabilized in comparison to the reference complex $\mathbf{5}$, which is expected due to the increased $\pi$-system of the pyterpy ligand L2. Since the metal-based HOMOs are unchanged, a stabilization of the MLCT-state can be expected. $N$-methylation of 1 significantly increases the $\pi$ accepting capabilities of the L2. Consequently, the LUMO of 2 is stabilized by $0.45 \mathrm{eV}$. Since the metalcentered HOMOs with mainly $\mathrm{t}_{2 \mathrm{~g}}$ character are only stabilized slightly, the HOMO-LUMO gap also decreases. A similar, but less pronounced effect is found for the bimetallic complex 3 . This indicates 
only a weak electronic interaction between the iron and the cobalt center, which is in agreement with the DFT-calculations above. Note that the $\mathrm{t}_{2 \mathrm{~g}}$ levels of $\mathbf{3}$ overlap with two additional molecular orbitals. Just like in complex 4 , these HOMO levels can be mainly assigned to two degenerated molecular orbitals located on both $\mathrm{dmgH}$ moieties. Consequently, in the case of $\mathbf{3}$, two distinct oxidation waves in the $\mathrm{CV}$ should be present, as confirmed by the measurements below.

In addition to the X-ray experiments, insights into the bonding properties are also given by IR spectroscopy. The IR spectroscopic response of complex $\mathbf{3}$ is dominated by the two fragments $\mathbf{1}$ and $\mathbf{4}$. The spectra of complexes $\mathbf{1}$ - $\mathbf{4}$ are shown in figure 5. Complex $\mathbf{4}$ was already thoroughly investigated by Thornton et al. ${ }^{[32]}$ while for $\mathbf{1}$ and $\mathbf{3}$, the calculation of the vibrational frequencies by DFT ( $c f$. figure S5-5 in SI for details) allowed identifying the most important bands as indicated in figure 5. The Co-Clstretching-vibration in 3 shifts by $8 \mathrm{~cm}^{-1}$ to higher wavenumbers compared to 4 . The underlying increased $\mathrm{Co}-\mathrm{Cl}$ bond strength causes a slightly weaker Co-N bond due to the trans-effect ( $c f$. also DFT calculations, table 1 and supporting information). Unfortunately, the stretching vibration of $\mathrm{Co}-\mathrm{N}_{\text {pyridine }}$ cannot be analyzed since it is overlapped by the signals of Fe-N vibrations. Nevertheless, this suggests a decreased basicity of the pyridine ring of the iron fragment $\mathbf{1}$ in comparison to isolated pyridine ${ }^{[6]}$ On the other hand, vibrations of $\mathbf{1}$ are not significantly influenced, either by methylation in complex $\mathbf{2}$ or by the coordination of the cobalt center.

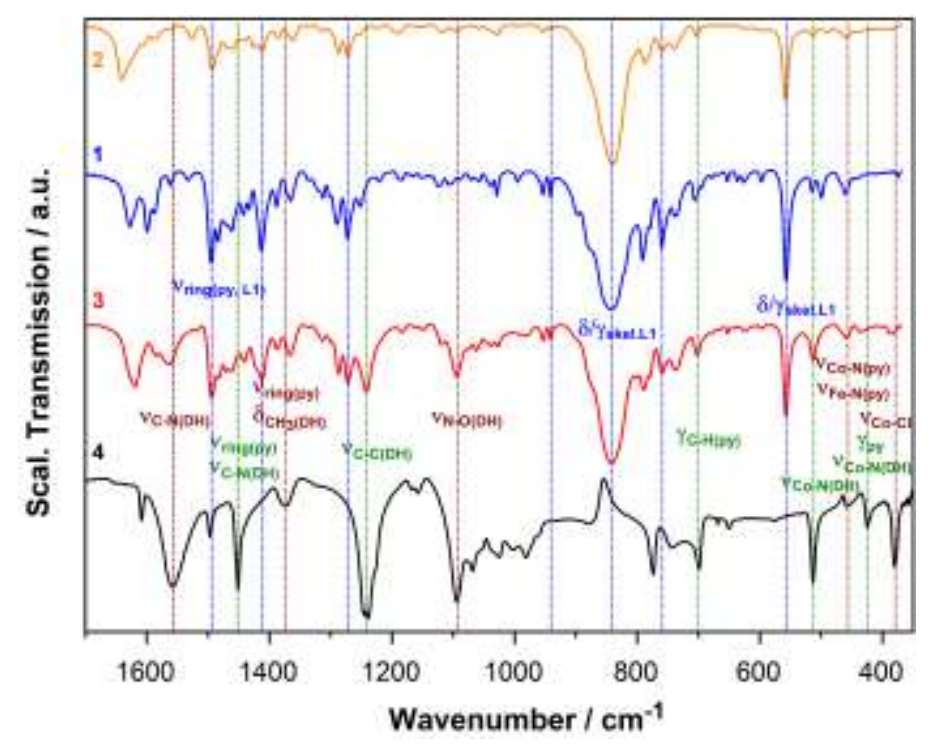

Figure 5. IR spectra of complexes 1 - 4 (KBr matrix). For better comparison, the most intense signals were scaled to 0.1 .

The electronic ground state spectra of complexes 1-5 in figure 6 provide the basis for the subsequent excited state characterization. For 1-3 and $\mathbf{5}$, the absorption spectra can be separated into two main parts. Consistent with the previously published results, MLCT transitions to the bis-NHC-ligand and the polypyridyl ligand are found above $350 \mathrm{~nm}$, while ligand based $\pi-\pi^{*}$ transitions dominate the 


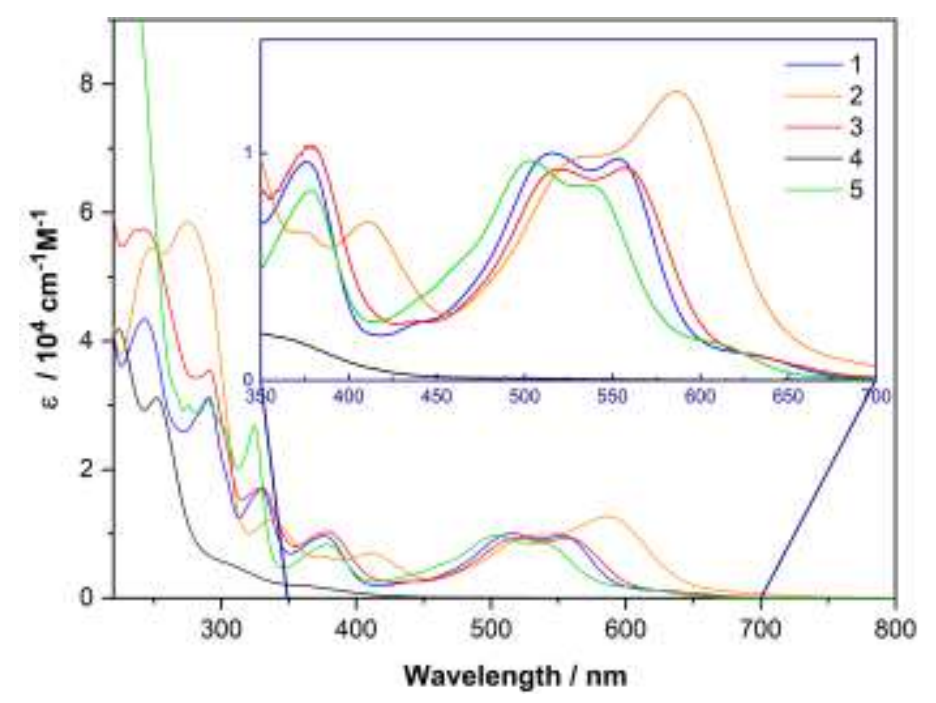

Figure 6. UV-Vis spectra of complexes $\mathbf{1}-\mathbf{5}$ in acetonitrile $\left(\mathrm{c}=10^{-5} \mathrm{~mol} / \mathrm{l}\right)$.

range below $350 \mathrm{~nm} .{ }^{[19]}$ The MLCT bands in $\mathbf{1}$ are bathochromic shifted in comparison to reference $\mathbf{5}$, with slightly increased extinction coefficients. This is in line with the electron-withdrawing effect of the pyridine ring. The absorption spectra of complex $\mathbf{1}$ and bimetallic complex $\mathbf{3}$ are very similar in the MLCT range. These transitions in $\mathbf{3}$ are still dominated by the iron fragment, since the absorption spectrum of $\mathbf{4}$, which was also measured to evaluate the contribution of the cobalt complex fragment in 3, exhibits only transitions in the UV area (black spectrum, figure 6). Therefore, the absorption spectrum of $\mathbf{3}$ can be described as a superposition of the spectra of $\mathbf{1}$ and $\mathbf{4}$. The coordination of the neutral fragment 4 to the nitrogen donor of $\mathbf{3}$ results in a small, but clear bathochromic shift $(5 \mathrm{~nm})$ in comparison to 1 . This indicates a small bond strength and therefore a weak electronic coupling, which was also confirmed by a significant fragmentation of $\mathbf{3}$ under ESI mass-spectrometry conditions (c.f. figure S1-7). This can be attributed to a small electron withdrawing effect of the cobalt fragment, which has also been found for related bimetallic iridium-cobalt systems. ${ }^{[24,33]}$ In contrast, 2 shows a significantly stronger bathochromic shift by $33 \mathrm{~nm}$ compared to non-methylated $\mathbf{1}$, since $\pi$-accepting capabilities of the polypyridyl ligand increase. This is in line with the results of Gros et al. ${ }^{[18]}$ Absorption characteristics of both $\mathbf{1}$ and $\mathbf{3}$ were investigated in solvents with different dielectric constants ( $c f$. S8-1 and S8-2 for details). The MLCT bands of chromophore $\mathbf{1}$ are largely independent of solvents and dielectric constants, at the exceptions of dichloromethane and nitromethane. The latter is known to be present in an acidic tautomeric form (aci-nitromethane), which is able to protonate the basic nitrogen of the pendant pyridyl ring. Therefore, a bathochromic shift similar to complex 2 was observed. The MLCT absorption of $\mathbf{3}$ dissolved in solvents with varying polarity as well did not correlate with parameters like $\mathrm{Et}_{30}$, dielectric constant or dipole moment, although the absorption bands shift over a wide spectral range. In both cases, changes of the dipole moments with optical excitation are rather small. ${ }^{[34]}$ 


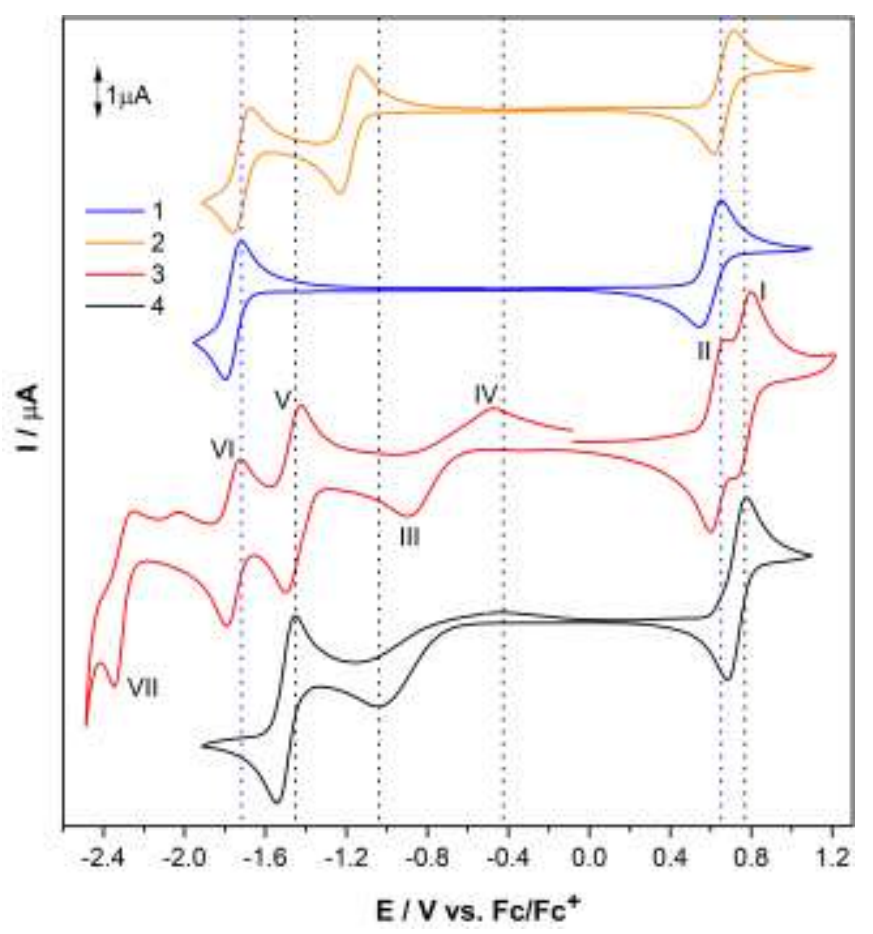

Figure 7. Cyclic voltammograms of 1-4 (acetonitrile, $100 \mathrm{mV} / \mathrm{s}$ )

The electrochemical behavior of $\mathbf{1 - 4}$ was investigated by cyclic voltammetry in acetonitrile. The results are shown in figure 7 . In the case of $\mathbf{1}$, a transition at $0.60 \mathrm{~V}$ corresponds to the reversible redox couple $\mathrm{Fe}^{\mathrm{II} / \mathrm{III}}$. At $-1.76 \mathrm{~V}$, a second reversible wave is attributed to the polypyridyl ligand based reduction at ligand L2. ${ }^{[13]} \mathrm{N}$-Alkylation at the pendant pyridyl ring in $\mathbf{2}$ results in an additional reversible reduction about $0.58 \mathrm{~V}$ anodic shifted compared to the reduction wave of $\mathbf{1}$, which is in line with other complexes containing a terminal pyridyl group. ${ }^{[22]}$ Corresponding to the DFT calculations, location of the electron at the pendent methylated pyridine ring after the first reduction of $\mathbf{2}$ is likely (cf. figure S5-4). Due to the electron-withdrawing effect of the quaternary nitrogen function, both the oxidation of Fe(II) and the second ligand based reduction occur at more anodic potentials. This is expected due to the lowering of the $\mathrm{t}_{2 \mathrm{~g}}$ orbitals and the improved $\pi$-accepting capabilities of the ligand, respectively ( $c f$. MO scheme in figure 4). In the case of the cobalt complex 4, an irreversible transition $\left(\mathrm{E}_{\mathrm{pc}}=-1.04 \mathrm{~V}\right)$ can be assigned to the $\mathrm{Co}^{\mathrm{II} / \mathrm{III}}$-reduction. For such complexes, the elimination of the chloride substituent during reduction is well known, ${ }^{[6,35,36]}$ which results in the irreversible behavior observed. The associated anodic transition is shifted to $-0.44 \mathrm{~V} .{ }^{[6]}$ Subsequently, the $\mathrm{Co}^{\mathrm{II}}$-center is quasi-reversibly reduced to $\mathrm{Co}^{\mathrm{I}}$ ( $c f$. SI for details). On the anodic site of the cyclic voltammogram, a reversible ligand-based wave at $+0.73 \mathrm{~V} \mathrm{vs}$. $\mathrm{Fc} / \mathrm{Fc}^{+}$is attributed to the oxidation of the dmgH moiety. ${ }^{[36]}$

The cyclic voltammograms of the bimetallic complex $\mathbf{3}$ can be interpreted as superposition of the single traces of 1 and 4, respectively, which is emphasized in figure 7. Starting from the anodic site, the transition I at $0.77 \mathrm{~V}$ is associated to the ligand-based oxidation on the cobalt fragment. This wave overlaps with the wave of the $\mathrm{Fe}^{\mathrm{II} / \mathrm{II}}$-couple (II, $0.63 \mathrm{~V}$, figure 7), as mentioned above. Both transitions are anodic shifted in comparison to the building blocks 1 and $\mathbf{4}$. Concerning the iron-based signal II, this slight shift is attributed to the coordination of the Lewis-acidic cobalt fragment. This matches with the more pronounced effect observed for complex 2 , which was obtained by methylation of $\mathbf{1}$. In the case of transition I, the anodic shift in $\mathbf{3}$ indicates a lower electron density in the $\mathrm{dmgH}$ ligand compared to 4, which consequently gives hint about the increased electron-withdrawing power and reduced Lewis basicity of the parental complex 1 compared to pyridine. This ligand effect, which was identically observed for a series of substituted cobaloximes by Coutsolelos et al, ${ }^{[6]}$ is in line with the anodic shift of Co-based reductions waves III and IV. The L2-based reduction shows a reversible transition wave at $1.76 \mathrm{~V}$. The potential observed is identical to the corresponding reduction in $\mathbf{1}$, which gives evidence for the weak bond strength to the cobalt center. Therefore, in comparison to $\mathbf{2}$, no reduction of the 
pendent pyridine ring was observed. The subsequent reduction attributed to the bis-NHC ligand L1 ($2.35 \mathrm{~V}, \mathrm{VII})$ is found to be irreversible. In our experiments, these corresponding transitions for $\mathbf{1}$ and $\mathbf{2}$ could only be observed in square wave voltammetry (see S6-5 and S6-10). During cyclic voltammetry, the first reduction waves were followed by non-reproducible curve-crossing reactions. Accordingly the reduced species are unstable under the measurement conditions.

All relevant electrochemical data are summarized in table 2. In addition, electronic parameters for 1-5 electronic absorption data are listed, including the corresponding electrochemical and optical band gaps.

\begin{tabular}{|c|c|c|c|c|c|c|c|c|}
\hline complex & $\begin{array}{l}\text { HOMO } \\
(\mathrm{eV})^{\text {a) }}\end{array}$ & $\begin{array}{l}\text { LUMO } \\
(\mathrm{eV})^{\text {a) }}\end{array}$ & $\begin{array}{l}\Delta \mathrm{E}_{\text {Homo- }} \\
\text { Lumo } \\
(\mathrm{eV})^{\mathrm{a})}\end{array}$ & $\begin{array}{l}\lambda_{\text {MLCT,abs. }}{ }^{\text {b) }}(\varepsilon) \\
\text { [nm, } \\
\left.\left(10^{4} \mathrm{~cm}^{-1} \mathrm{M}^{-1)}\right)\right]\end{array}$ & $\begin{array}{l}\Delta \mathrm{E}_{\mathrm{o}}^{\mathrm{c})} \\
{[\mathrm{eV}]}\end{array}$ & $\begin{array}{l}E_{o x}^{d)} \\
{[V]}\end{array}$ & $\begin{array}{l}\mathrm{E}_{\text {red }}{ }^{\mathrm{d})} \\
{[\mathrm{V}]}\end{array}$ & $\begin{array}{l}\Delta \mathrm{E}_{\mathrm{p}}^{\mathrm{e})} \\
{[\mathrm{eV}]}\end{array}$ \\
\hline 1 & -5.4082 & -2.7411 & 2.67 & $\begin{array}{l}375(0.96) \\
515(1.00) \\
553(0.98)\end{array}$ & $\begin{array}{l}3.31 \\
2.41 \\
2.24 \\
\end{array}$ & $0.60(r)$ & $\begin{array}{l}-1.76(\mathrm{r}) \\
-2.31 \text { (ir) }\end{array}$ & $\begin{array}{l}2.36 \\
2.91\end{array}$ \\
\hline 2 & -5.5242 & -3.1869 & 2.34 & $\begin{array}{l}374(0.66) \\
411(0.70) \\
538(0.99) \\
586(1.27) \\
\end{array}$ & $\begin{array}{l}3.32 \\
3.02 \\
2.30 \\
2.12 \\
\end{array}$ & $0.66(r)$ & $\begin{array}{l}-1.19(\mathrm{r}) \\
-1.72(\mathrm{r}) \\
-2.42(\mathrm{ir})\end{array}$ & $\begin{array}{l}1.85 \\
2.38 \\
3.08\end{array}$ \\
\hline 3 & -5.4511 & -2.8616 & 2.59 & $\begin{array}{l}379(1.03) \\
520(0.93) \\
558(0.94)\end{array}$ & $\begin{array}{l}3.27 \\
2.38 \\
2.22\end{array}$ & $\begin{array}{l}0.77 \\
0.63\end{array}$ & $\begin{array}{l}-0.90 \text { (ir) } \\
-1.47 \\
-1.76 \\
-2.32 \text { (ir) }\end{array}$ & $\begin{array}{l}2.39 \\
2.95 \\
\end{array}$ \\
\hline 4 & $-5,3740$ & $-2,2430$ & 3.13 & - & & $0.73(r)$ & $\begin{array}{l}-1.04 \text { (ir) } \\
-1.50(\mathrm{qr})\end{array}$ & \\
\hline 5 & -5.3687 & -2.5912 & 2.78 & $\begin{array}{l}379(0.84) \\
503(0.98) \\
538(0.86)\end{array}$ & $\begin{array}{l}3.27 \\
2.46 \\
2.24 \\
\end{array}$ & $0.56(r)$ & $\begin{array}{l}-1.89(\mathrm{r}) \\
-2.33(\mathrm{ir})\end{array}$ & $\begin{array}{l}2.45 \\
2,89\end{array}$ \\
\hline
\end{tabular}

a) def2-TZVPP, TPSSh, SMD (acetonitrile) b) $\mathrm{CH}_{3} \mathrm{CN}, 10^{-5} \mathrm{~mol} / \mathrm{l} \mathrm{c)} \Delta \mathrm{E}_{\mathrm{p}}=$ optical band gap, $\mathrm{E}_{\mathrm{MLCT}}$ d)

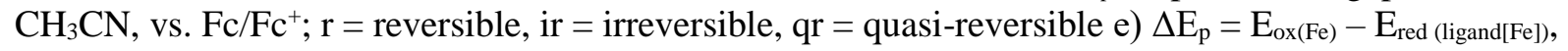
potentiometrically determined band gap

Correlation of the electrochemical band gap $\Delta \mathrm{E}_{\mathrm{p}}\left(\Delta \mathrm{E}_{\mathrm{p}}=\mathrm{E}_{\mathrm{ox}}-\mathrm{E}_{\mathrm{red}}\right)$ with the optical band gap $\Delta \mathrm{E}_{\mathrm{o}}\left(\Delta \mathrm{E}_{\mathrm{o}}\right.$ $=\mathrm{E}_{\mathrm{MLCT}}$ ) attributes the low-energy MLCT absorptions to the polypyridyl ligand L2, whereas the absorption band at $374-379 \mathrm{~nm}$ can be assigned to the bis-NHC ligand L1. Since the latter band gaps are only marginally influenced by modification of ligand L2, no ligand interaction is present and the ligand effects can be considered as independent. Therefore, tuning of physicochemical properties in such complexes should be possible by separate modifications at each of the ligands.

As (in contrast to 3 ) both reversible one-electron oxidation and reduction transitions of $\mathbf{1}$ are well separated, spectro-electrochemical experiments were performed in order to investigate absorption properties of the oxidized and reduced species, respectively. As shown in figure 8, the bulk oxidation of 1 in acetonitrile is fully reversible. Isosbestic points indicate the conversion between only two species. On formation of iron(III) species, the MLCT absorption nearly vanishes due to almost complete degradation of the chromophore. Instead, at wavelengths larger than around $585 \mathrm{~nm}$, a broad absorption band arises, which is expected to have ligand-to-metal charge transfer (LMCT) character. ${ }^{[37]}$

In contrast, reduction occurred only under drastic conditions $(-2.5 \mathrm{~V})$ and was found to be not reversible. The absence of clear isosbestic points during reduction indicates that $\mathbf{1}$ is unstable on a longer time-scale ( $c f$. figure S7-1 for details), whereas the cyclic voltammetry revealed reversible electrode transitions. Thus, 1 differs significantly from the terpy analogue $\mathbf{5}$, which was found to behave fully reversible during bulk electrolysis. ${ }^{[13,19]}$ 


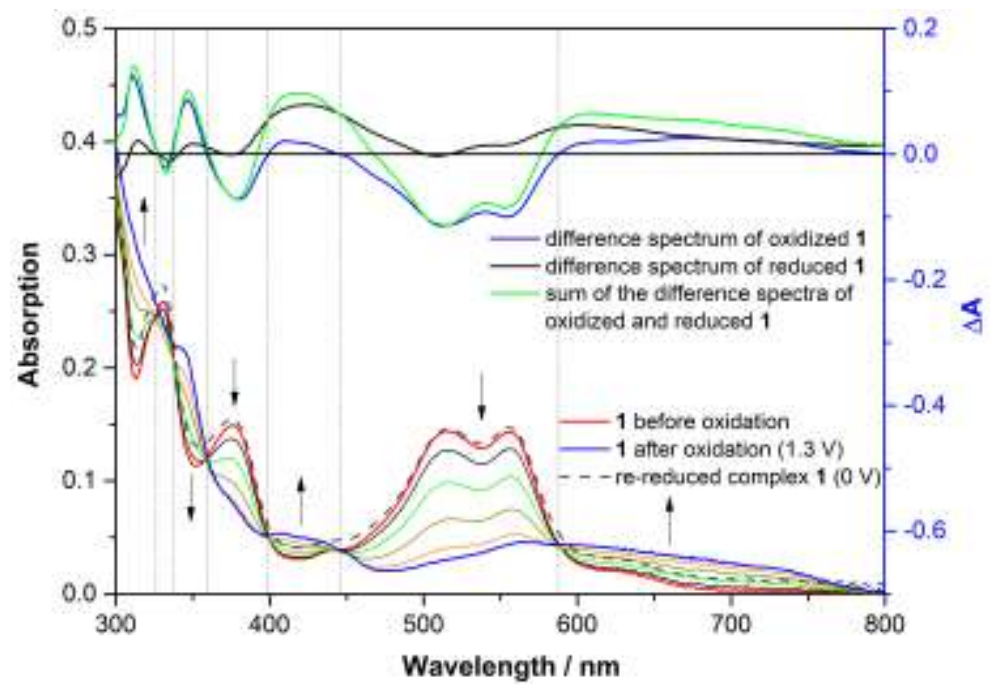

Figure 8. Top: Difference Spectrum of oxidized 1 (blue), reduced 1 (black) and linear combination (green). Bottom: Changes in UV-Vis absorption during oxidation of $\mathbf{1}$ at $1.3 \mathrm{~V}$ and after re-reduction at $0 \mathrm{~V}$.

After re-oxidation, a new species was formed, with absorption bands significantly different from the original 1. Due to the low concentrations during bulk electrolysis and the presence of large amounts of conducting salt, further insights into these redox reactions with ESI or NMR were not possible. Therefore, a recently developed X-ray spectro-electrochemical cell that allows recording high-speed XANES and EXAFS spectra of oxidized and reduced species in-situ was employed. This cell allows for the fluorescence measurements required for several techniques with inert conditions maintained throughout.

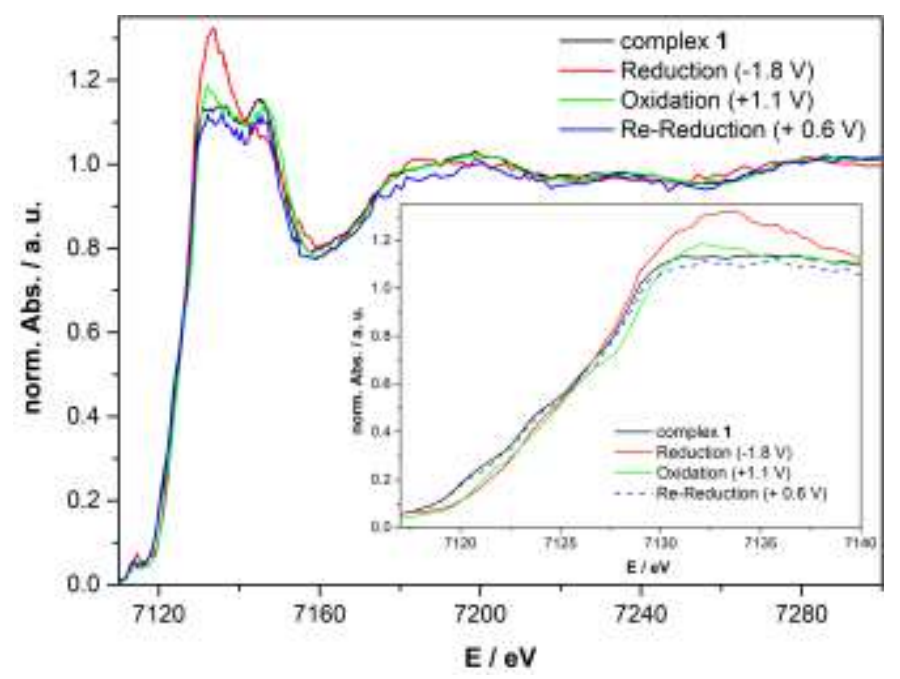

Figure 9. XANES spectra of 1. Black: initial complex, green: after oxidation at $+1.1 \mathrm{~V}$ and grey: after re-reduction at $+0.6 \mathrm{~V}$, red: spectrum after reduction $(-1.8 \mathrm{~V})$. The potentials refer to the $\mathrm{Ag} / \mathrm{Ag}\left(\mathrm{NO}_{3}\right)$ reference electrode. Inset: Absorption edges.

Applying a positive voltage of $1.1 \mathrm{~V}$ to $\mathbf{1}$ dissolved in acetonitrile, the XANES edge shifts to higher energies, which is expected due to the formation of Fe(III) (figure 9). The shift of about $1 \mathrm{eV}$ is rather small, but agrees with results by Uhlig, Persson et al., who observed edge shifts even smaller $1 \mathrm{eV} .^{[38]}$ The edge shift in the XANES spectra, respectively clearly shows that indeed metal-based orbitals are involved in the oxidation process. The bond lengths in the first EXAFS shell seemingly decrease, while the ligand sphere itself remains intact. The EXAFS spectra are shown in figure S3-1 of the supplementary information. Fully consistent with the spectro-electrochemical experiments, the measured shift is completely reversible on re-reduction. In contrast, the EXAFS spectra and their 
Fourier-transformed spectra, respectively observed after reduction at $-1.8 \mathrm{~V}$ differ significantly from the spectra related to the oxidation. Most pronounced, the carbon shell at $2.8 \AA$ almost vanished and a shell at around $3.5 \AA$ arises instead. Due to the significant change in the ligand system, which probably is related to a decomposition of $\mathbf{1}$, a back-oxidation failed. In addition, upon reduction of $\mathbf{1}$ the absorption edge does not show the characteristic shift, which would be expected for metal based redox processes. This indeed indicates a ligand centered process, in agreement with the preceding results.

After thorough ground state characterization, excited-state investigations by ultrafast femtosecond (fs) optical absorption spectroscopy are mandatory to obtain insights into the electron dynamics. Figure 10 gives the evolution of the transient absorption (TA) spectra in acetonitrile upon photoexcitation at 400 $\mathrm{nm}$ for $\mathbf{1}$ and $\mathbf{3}$ (see figures S9-1 and S9-2 in the supporting information for the corresponding TA spectra measured in propylene carbonate and dimethyl sulfoxide). The standard singular-value decomposition (SVD) analysis delivers two decay-associated spectra (DAS) and their time constants are summarized in Table 3 and 4. In all cases, the DAS1 of the short lived decay component ( $\sim$ ps) is similar to the bleach in the blue spectral region and exhibits a distinct ESA band in the red spectral region. The lifetime assigned to this DAS tends to be longer in polar solvents and also slightly increases from $\mathbf{1}$ to $\mathbf{3}$. In contrast, DAS2 of the long lived component ( 100 ps) resembles the inverse of the original absorption spectrum. DAS2 is solvent-dependent to a higher extent and no clear trend can be found by comparing 1 and 3.

Based on previously reported work, ${ }^{[13,16,17]}$ the short lived component is assigned to the population of the ${ }^{3}$ MLCT state in the Fe-moiety, while the longer liver component is associated to the population of the triplet or quintet ${ }^{3 / 5} \mathrm{MC}$ state. Strong support for the assignment of DAS1 to MLCT states is given by the fact that it shows very close similarity with the linear combination of the difference absorption spectra of oxidized and reduced 1, respectively, which are given in the top part of figure 8. Comparison with reported studies on related complexes surprisingly reveals a closer spectral resemblance of the short-lived DAS1 with the one of $\left[\mathrm{Fe}(\mathrm{L} 3)_{2}\right]\left[\mathrm{BPh}_{4}\right]_{2}$ (with L3 = 2,6-bis[3-isopropylimidazol-2-ylidene]pyridine) than of $[\mathrm{Fe}(\mathrm{L} 1)($ terpy $)]\left[\mathrm{BPh}_{4}\right]_{2}\left(\mathbf{5}^{\prime}\right) \cdot{ }^{[13]} \mathrm{In}$ addition, the MLCT states are further stabilized by solvents of high dielectric constant, which gives hint to charge-separated excited states. 

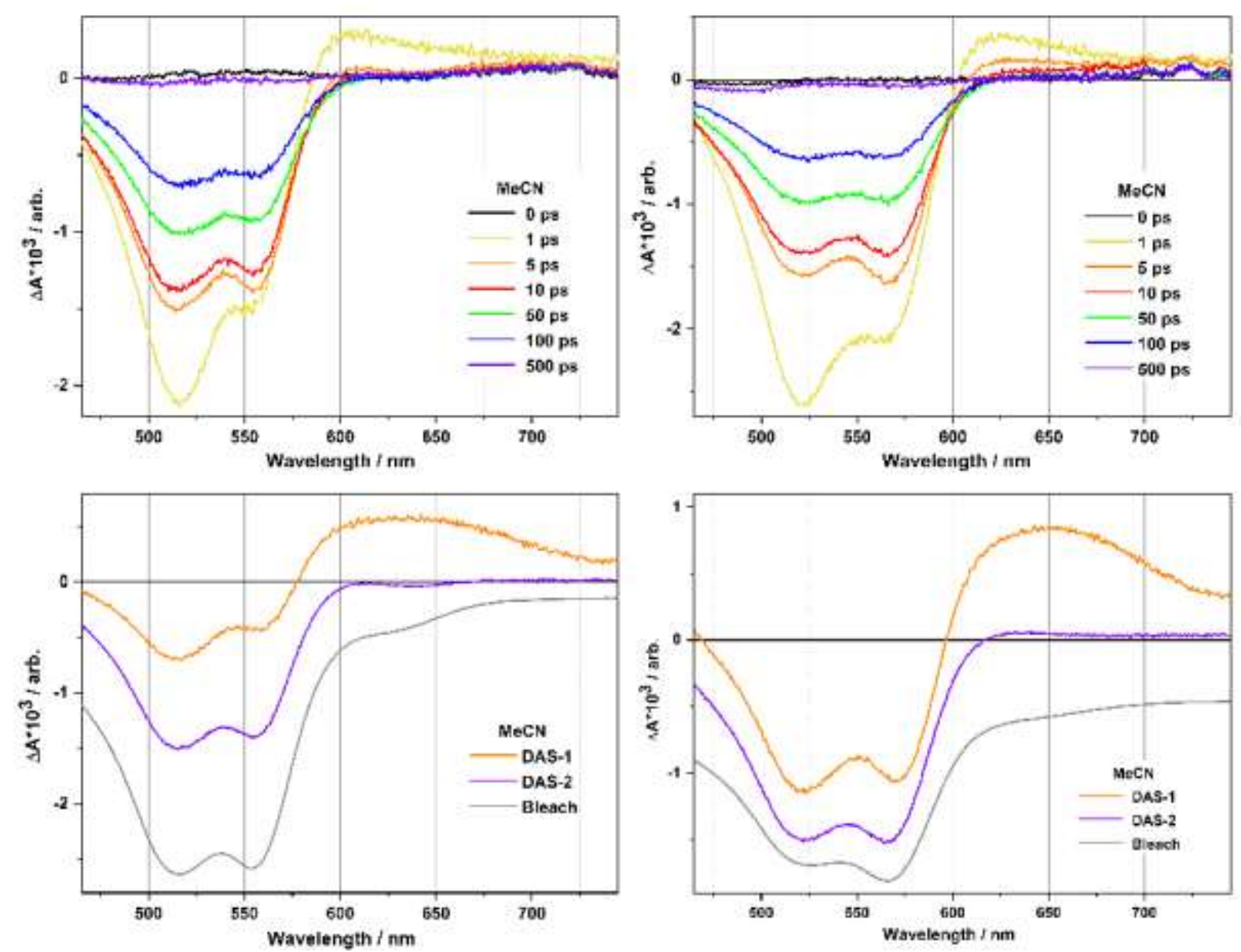

Figure 10. Left: Top) TA spectra of $\mathbf{1}$ in $\mathrm{MeCN}$ at the indicated selected delay times after optical excitation at $400 \mathrm{~nm}$. Bottom) Decay associated spectra (DAS) of the two exponential components (orange and purple traces, see main text and table 3). The negative of the steady-state absorption (grey trace) is displayed and scaled for comparison with the bleach signal). Right: Top) TA spectra of $\mathbf{3}$ in $\mathrm{MeCN}$ at the indicated selected delay times after optical excitation at $400 \mathrm{~nm}$. Bottom) Decay associated spectra (DAS) of the two exponential components (orange and purple traces, see main text and table 4). The negative of the steady-state absorption (grey trace) is displayed and scaled for comparison with the bleach signal).

Table 3: Exponential time constants of the two decay associated spectra (DAS) of 1

\begin{tabular}{|l|l|l|c|}
\hline Solvent & dielectric constant $\varepsilon_{\mathrm{r}}^{[39]}[\mathrm{a}]$ & $\mathrm{DAS} 1, \tau_{1}(\mathrm{ps})$ & $\mathrm{DAS} 2, \tau_{2}(\mathrm{ps})$ \\
\hline MeCN & 35.94 & $1.1(0.12)$ & $139(0.12)$ \\
\hline DMSO & 46.45 & $0.7(0.12)$ & $90(0.12)$ \\
\hline PC & 64.92 & $2.0(0.12)$ & $146(0.12)$ \\
\hline
\end{tabular}

[a] $25^{\circ} \mathrm{C}$

Table 4: Exponential time constants of the two decay associated spectra (DAS) of 3

\begin{tabular}{|l|l|l|l|}
\hline Solvent & dielectric constant $\varepsilon_{\mathrm{r}}^{[39]}[\mathrm{a}]$ & $\mathrm{DAS} 1, \tau_{1}(\mathrm{ps})$ & $\mathrm{DAS} 2, \tau_{2}(\mathrm{ps})$ \\
\hline MeCN & 35.94 & $1.4(0.12)$ & $118(0.12)$ \\
\hline DMSO & 46.45 & $2.4(0.12)$ & $114(0.12)$ \\
\hline PC & 64.92 & $2.3(0.12)$ & $140(0.12)$ \\
\hline
\end{tabular}

[a] $25^{\circ} \mathrm{C}$

The obtained time constants and assignments prove the lifetime of the MLCT states to be actually longer in the assembled dyad $\mathbf{3}$ than in the isolated chromophore 1. Looking at the TA experiments measured in acetonitrile, the increasing ${ }^{3} \mathrm{MLCT}$ lifetime in the order $\mathrm{R}=-\mathrm{H}(\mathbf{5})<\mathrm{R}=-4$-pyridyl $(\mathbf{1})<\mathrm{R}=-$ $\mathrm{CoCl}(\mathrm{dmgH})_{2}(\mathbf{3})\left(\mathrm{R}=\right.$ substituent in 4 '-position at terpyridine ring of $\left.[\mathrm{FeL} 1 \text { (terpy) }]^{2+}\right)$ is in line with 
the decreasing LUMO energies as discussed in figure 4 ( $c f$. also ref. 13). In addition, the $\pi$-system is enlarged in the excited state by the pyridine rings in the backbone of terpyridine, which is also known to stabilize the LUMO energies. ${ }^{[40]}$

Since the metal-centered molecular orbitals $\left(\mathrm{e}_{\mathrm{g}}{ }^{*}\right)$ are less influenced by the modifications in the ligand backbone, ligand field splitting and consecutively the MC energies are expected to change to a much lower extend. However, much to our surprise, the MC lifetimes were found to decrease with increasing MLCT lifetime, which corresponds to a smaller relaxation barrier into the ground state. Since a stabilization of the $t_{2 g}$ orbitals with increasing $\pi$-accepting properties of the polypyridyl ligand can be expected in accordance with classical ligand field theory ( $c f$. figure 4), an additional destabilization of the $\mathrm{MC}$ levels in relation to the ground state seems plausible. A similar solvent-dependent effect was observed for $\left[\mathrm{Fe}(\text { bipy })(\mathrm{CN})_{4}\right]^{2-}$ by Kjær et al.$^{[12,41]}$ and could also occur for the complexes discussed here. Therefore, this observation will be investigated in the future with time resolved X-ray studies in different solvents and complemented with excited state calculations.

In summary, the presented experimental results give evidence for an elongation of the ${ }^{3}$ MLCT lifetime mainly by lowering the LUMO and MLCT energy, respectively. In that sense, the results are in line with a previous study on homoleptic NHC based iron(II) complexes, in which the MLCT lifetime could be prolonged by introducing carboxyl groups in the ligand backbone. This resulted in lower MLCT state energies with the MC state energies remaining unaffected. ${ }^{[8,15,16]}$

\section{Conclusion}

In conclusion, the first bimetallic dyad connecting a heteroleptic NHC-based photosensitizer with a cobalt dimethylglyoxime motif (3) could be introduced while studying the ground and excited state of heteroleptic iron complexes. As bridging ligand between the two metal centers, 4'-(4"'-pyridyl)$2,2^{\prime}: 6^{\prime}, 2^{\prime \prime}$-terpyridine (pyterpy) is employed. In the present study, this dyad is compared to the isolated chromophore $\mathbf{1}$ and the corresponding complex $\mathbf{2}$ with a methyl group at the pendent pyridine ring. It is remarkable that both ligands in these heteroleptic complexes behave electronically independent, which allows tuning of the photophysics in such complexes at the two ligands independently.

Detailed ground state characterization by the hard X-ray methods by CtC-XES, VtC-XES and HERFDXANES in combination with (TD-)DFT calculations revealed a decreasing energy of the LUMO states with increasing electron accepting abilities of the pendant substituent at the terpy motif. The LUMO energies were found to decrease in the order $\mathbf{5}>\mathbf{1}>\mathbf{3}>\mathbf{2}$, whereas the metal centered orbitals barely exhibit any energetic differences. Electrochemical and electronic absorption measurements showed additionally a rather weak interference of the individual signatures of the cobalt and the iron center in the dyad $\mathbf{3}$. Although this indicates that the cobalt dimethylglyoxime motif simply acts as a Lewis acid the dative bond from the iron to the cobalt fragment is proved by the crystal structure and mass spectrometric measurements. Unfortunately, no inter-metal electron transfer could be detected on the time-scale of transient absorption experiments. The effect of the Co center on the photophysics of the iron fragment is however obvious. $\mathbf{1}$ and $\mathbf{3}$ show higher MLCT state lifetimes with decreasing LUMO energies in comparison to $\mathbf{5}$, whereas the MC states are energetically affected to a much lower extent. In the same sense, the MC state lifetime was found to decrease. The key results are summarized in figure 11. 


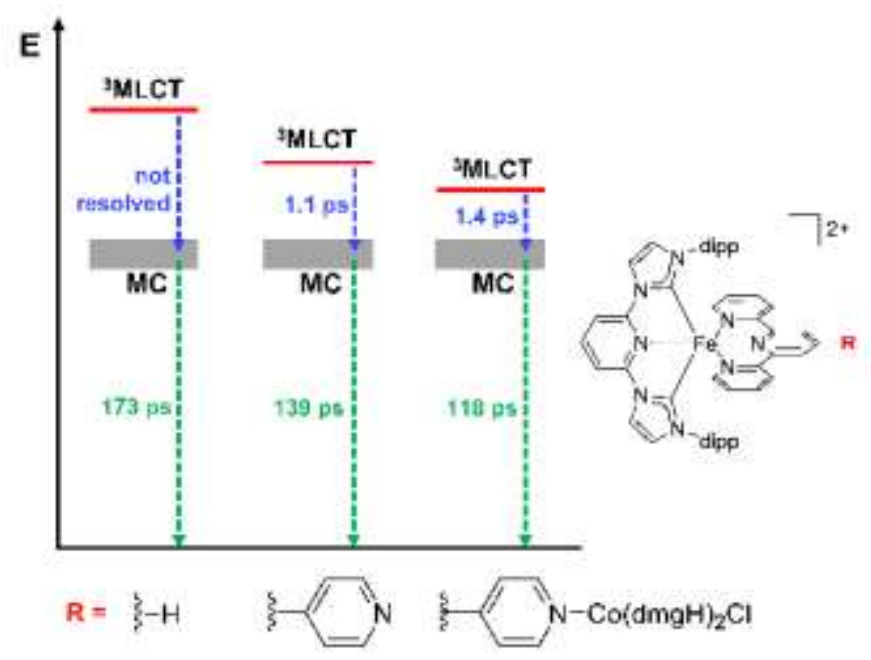

Figure 11. Simplified Jablonski scheme for complexes 1, 3 and 5 measured in acetonitrile.

Complementary to our previous study, which proved the MLCT state lifetime to increase with increasing NHC donor count and MC energy, two basic strategies, namely increasing MC state energy and decreasing the MLCT state energy, have been systematically investigated and verified now in the present study. Furthermore, applying polar solvents with high dielectric constants were found to increase the lifetimes of the charge-separated MLCT states. Although no evidence for a charge transfer to the cobalt center could be provided by the various measurements, the obtained results merge into a strategy to achieve photocatalytically active $\mathrm{Fe}$-Co dyads with efficient charge separation. Especially tuning the electron withdrawing properties of the cobalt fragment is crucial: On the one hand, based on the results presented here, the MLCT state lifetimes involving the iron fragment are expected to become longer with increased "pull"-strength of the Co fragment, and on the other hand access is given to low-lying reversible reduction levels probably localized on the linker pyridine ring L2, as it was proven for $\mathbf{2}$. Employing these principles should yield active proton reduction dyads synthesized completely out of non-noble and Earth-abundant metals in the near future.

\section{Experimental Section}

SYNTHESIS. Reactions were carried out under an argon atmosphere using standard Schlenk techniques. Solvents were dried over molecular sieves in a MBraun Solvent Purification System or distilled over sodium with benzophenone as an indicator in the case of THF, respectively. Solvents were degassed prior to use by standard procedures. All chemicals were purchased from Sigma-Aldrich, TCI, or Fisher and used without further purification. NMR spectra were recorded using either a Bruker Ascent 700, Avance 500 or Avance 300 device. IR spectra were recorded in a $\mathrm{KBr}$ matrix using a Bruker Vertex 70. Mass spectra (ESI) were recorded with a Waters Synapt G2 quadrupole - time-of-flight spectrometer. The solvent used is denoted for every substance.

Synthesis of L2 was carried out by a literature procedure. ${ }^{[22]}$ The five-coordinated Fe(II) precursor [Fe[L1]Br 2 with $\mathrm{L} 1=2,6$-bis[3-(2,6-diisopropylphenyl)-imidazol-2-ylidene]pyridine was synthesized according to literature procedures ${ }^{[13,19,27]}$ synthesis of ligand L1 is described elsewere. ${ }^{[27,43]}$ Synthesis of 4 was performed by a protocol of Schrauzer et al.. ${ }^{[28]}$

Synthesis of 1. L1-H (300 mg, $0.433 \mathrm{mmol})$ was suspended in THF (20 mL). The mixture was cooled to $-80^{\circ} \mathrm{C}$ and $\left[\mathrm{Fe}\left(\mathrm{N}\left(\mathrm{SiMe}_{3}\right)_{2}\right)_{2}\right]_{2}(163 \mathrm{mg}, 0.216 \mathrm{mmol})$ in $\mathrm{THF}(6 \mathrm{~mL})$ was added. The mixture was slowly warmed to room temperature und stirred overnight. 4'-(4-pyridyl)-2,2':6',2"-terpyridine (134 mg, $0.433 \mathrm{mmol}$ ) was added in one portion and the mixture was stirred again overnight. The solvent was removed in vacuum and the residue was dissolved in water. Residual solid was removed by filtration and a saturated $\mathrm{KPF}_{6}$-solution in water was added dropwise to precipitate a purple colored solid. The product was recrystallized by diffusion of chloroform into an acetone solution $(267 \mathrm{mg}, 52 \%) .{ }^{1} \mathrm{H}$ NMR 
(500 MHz, Acetone-d6) $\delta 8.89-8.87(\mathrm{~m}, 2 \mathrm{H}), 8.86-8.82(\mathrm{~m}, 3 \mathrm{H}), 8.77(\mathrm{dt}, \mathrm{J}=7.8,1.2 \mathrm{~Hz}, 2 \mathrm{H}), 8.62$ $(\mathrm{d}, \mathrm{J}=8.2 \mathrm{~Hz}, 2 \mathrm{H}), 8.54(\mathrm{~s}, 2 \mathrm{H}), 8.12(\mathrm{td}, \mathrm{J}=7.7,1.4 \mathrm{~Hz}, 2 \mathrm{H}), 7.89-7.76(\mathrm{~m}, 2 \mathrm{H}), 7.59(\mathrm{~d}, \mathrm{~J}=2.2 \mathrm{~Hz}$, $2 \mathrm{H}), 7.53(\mathrm{ddd}, \mathrm{J}=5.6,1.4,0.7 \mathrm{~Hz}, 2 \mathrm{H}), 7.37(\mathrm{ddd}, \mathrm{J}=7.2,5.6,1.3 \mathrm{~Hz}, 2 \mathrm{H}), 7.11(\mathrm{t}, \mathrm{J}=7.8 \mathrm{~Hz}, 2 \mathrm{H})$, $6.90(\mathrm{~d}, \mathrm{~J}=7.8 \mathrm{~Hz}, 4 \mathrm{H}), 0.94$ (hept, $\mathrm{J}=6.5 \mathrm{~Hz}, 4 \mathrm{H}), 0.73(\mathrm{~d}, \mathrm{~J}=6.6 \mathrm{~Hz}, 12 \mathrm{H}), 0.63(\mathrm{~d}, \mathrm{~J}=6.7 \mathrm{~Hz}, 12 \mathrm{H})$. ${ }^{13} \mathrm{C}$ NMR (176 MHz, Acetone-d6) $\delta$ 198.82, 158.98, 157.38, 156.58, 153.26, 151.84, 145.82, 144.98, 144.92 , 143.42, 137.95, 134.79, 132.19, 130.86, 127.97, 126.15, 124.32, 122.63, 119.51, 118.77, 109.51, 28.12, 26.73, 23.74. HRMS (ESI) $\mathrm{m} / \mathrm{z} 448.69690 .5\left[\mathrm{M}-2 \mathrm{PF}_{6}\right]^{2+}$ (calcd for $\mathrm{C}_{55} \mathrm{H}_{55} \mathrm{FeN}_{9}$ 897.3930).

Synthesis of 2. The raw product [FeL1L2][Br $]_{2}(100 \mathrm{mg}, 0.0945 \mathrm{mmol})$, which was obtained by synthesis of $\mathbf{1}$, was dissolved in acetonitrile $(25 \mathrm{~mL})$. Methyl iodide $(1.59 \mathrm{~mL}, 25.5 \mathrm{mmol})$ was added and the mixture was heated at $82{ }^{\circ} \mathrm{C}$ for 90 minutes. After cooling to room temperature, the solvent was removed by distillation and the residue was dissolved in water $(50 \mathrm{~mL})$. After filtration, a saturated solution of $\mathrm{KPF}_{6}$ in water was added dropwise. The crystallized solid was filtered off and washed with water $(20 \mathrm{~mL})$. The violet-colored solid was dried in vacuum to give $2(92.5 \mathrm{mg}, 77 \%)$. ${ }^{1} \mathrm{H}$ NMR (500 $\mathrm{MHz}$, Acetone-d6) $\delta 9.28-9.20(\mathrm{~m}, 2 \mathrm{H}), 8.88-8.84(\mathrm{~m}, 1 \mathrm{H}), 8.82(\mathrm{~d}, \mathrm{~J}=2.2 \mathrm{~Hz}, 2 \mathrm{H}), 8.77-8.73(\mathrm{~m}$, $4 \mathrm{H}), 8.71-8.66(\mathrm{~m}, 2 \mathrm{H}), 8.63(\mathrm{~d}, \mathrm{~J}=8.3 \mathrm{~Hz}, 2 \mathrm{H}), 8.13(\mathrm{td}, \mathrm{J}=7.7,1.4 \mathrm{~Hz}, 2 \mathrm{H}), 7.59(\mathrm{~d}, \mathrm{~J}=2.2 \mathrm{~Hz}$, 2H), 7.54 (ddd, J = 5.6, 1.4, 0.7 Hz, 2H), 7.40 (ddd, J = 7.2, 5.6, 1.3 Hz, 2H), 7.10 (t, J = 7.8 Hz, 2H), $6.87(\mathrm{~d}, \mathrm{~J}=7.8 \mathrm{~Hz}, 4 \mathrm{H}), 4.72(\mathrm{~s}, 3 \mathrm{H}), 0.89$ (hept, J = 6.5 Hz, 4H), $0.71(\mathrm{~d}, \mathrm{~J}=6.6 \mathrm{~Hz}, 12 \mathrm{H}), 0.61(\mathrm{~d}, \mathrm{~J}$ $=6.6 \mathrm{~Hz}, 12 \mathrm{H}) .{ }^{13} \mathrm{C}$ NMR $(126 \mathrm{MHz}$, Acetone-d6) $\delta 198.13,159.87,156.92,156.20,153.24,152.63$, $147.49,145.85,144.03,139.41,138.15,134.63,132.26,130.93,128.32,126.46^{*}, 124.45,118.99$, 118.94, 109.83, 48.95, 28.14, 26.78, 23.72. *superposition of two signals. HRMS (ESI) m/z 304.1401 $0.33\left[\mathrm{M}-3 \mathrm{PF}_{6}\right]^{3+}\left(\right.$ calcd for $\left.\mathrm{C}_{56} \mathrm{H}_{58} \mathrm{FeN} 9912.4165\right)$.

Synthesis of 3. $\mathrm{CoCl}_{2} * 6 \mathrm{H}_{2} \mathrm{O}(21.0 \mathrm{mg}, 0.0884 \mathrm{mmol})$ and dimethylglyoxime (22.5 mg, $\left.0.194 \mathrm{mmol}\right)$ were dissolved in ethanol $(95 \%, 10 \mathrm{~mL})$ and heated to $70{ }^{\circ} \mathrm{C} .1(105 \mathrm{mg}, 0.0884 \mathrm{mmol})$ dissolved in acetone $(3 \mathrm{~mL})$ was added and the solution was cooled to room temperature by removing the heating bath. Then oxygen was bubbled into the solution for $30 \mathrm{~min}$. Subsequently, the solvents were removed in vacuum. The violet raw product was crystallized twice by diffusion of chloroform into an acetone solution to obtain 3 as violet colored needles $(60 \%, 80.2 \mathrm{mg}) .{ }^{1} \mathrm{H}$ NMR $(500 \mathrm{MHz}$, Acetone-d6) $\delta 8.88$ $-8.81(\mathrm{~m}, 3 \mathrm{H}), 8.69(\mathrm{~d}, \mathrm{~J}=8.0,1.1 \mathrm{~Hz}, 2 \mathrm{H}), 8.62(\mathrm{~d}, \mathrm{~J}=8.2 \mathrm{~Hz}, 2 \mathrm{H}), 8.49(\mathrm{~d}, \mathrm{~J}=6.4 \mathrm{~Hz}, 2 \mathrm{H}), 8.47(\mathrm{~s}$, $2 \mathrm{H}), 8.12(\mathrm{td}, \mathrm{J}=7.7,1.4 \mathrm{~Hz}, 2 \mathrm{H}), 7.89-7.79(\mathrm{~m}, 2 \mathrm{H}), 7.57(\mathrm{~d}, \mathrm{~J}=2.1 \mathrm{~Hz}, 2 \mathrm{H}), 7.55-7.48(\mathrm{~m}, 2 \mathrm{H})$, $7.37(\mathrm{ddd}, \mathrm{J}=7.2,5.6,1.3 \mathrm{~Hz}, 2 \mathrm{H}), 7.05(\mathrm{t}, \mathrm{J}=7.8 \mathrm{~Hz}, 2 \mathrm{H}), 6.86(\mathrm{~d}, \mathrm{~J}=7.8 \mathrm{~Hz}, 4 \mathrm{H}), 2.45(\mathrm{~s}, 12 \mathrm{H}), 0.89$ (hept, J = 6.6 Hz, 4H), $0.69(\mathrm{~d}, \mathrm{~J}=6.6 \mathrm{~Hz}, 12 \mathrm{H}), 0.60(\mathrm{~d}, \mathrm{~J}=6.6 \mathrm{~Hz}, 12 \mathrm{H}) .{ }^{13} \mathrm{C}$ NMR $(126 \mathrm{MHz}$, Acetoned6) $\delta 198.50,159.53,157.29,156.64,153.54,153.51,152.74,148.87,146.06,143.90,142.56,138.30$, 134.93, 132.45, 131.03, 128.34, 126.51, 125.29, 124.58, 119.72, 119.07, 109.85, 28.31, 26.90, 24.03, 13.19. HRMS (ESI) $\mathrm{m} / \mathrm{z} 610.69790 .5\left[\mathrm{M}-2 \mathrm{PF}_{6}\right]^{2+}$ (calcd for $\mathrm{C}_{63} \mathrm{H}_{69} \mathrm{FeN}_{13} \mathrm{O}_{4} \mathrm{ClCo} 1221.3965$ ).

Crystal Structure Determination: The intensity data of $\mathbf{1}$ and $\mathbf{3}$ were recorded using a Bruker SMART CCD area-detector diffractometer with a graphite-monochromated $\operatorname{MoK}_{\alpha}$ radiation $(\lambda=0.71073 \AA)$ at $\mathrm{T}=130(2) \mathrm{K}$. The intensity data of $\mathbf{2}$ were collected using a diffractometer equipped with a Photon II $\mathrm{CCD}$ area detector, a multilayer mirror monochromator and $\mathrm{a} \mathrm{CuK}_{\alpha}(\lambda=1.54178 \AA$ ) micro-focus source at $120(2) \mathrm{K}$. Structure solutions were carried out by direct methods, ${ }^{[44]}$ full-matrix least squares refinement based on $\boldsymbol{F}^{2}{ }^{[44]}$ All but $\mathrm{H}$-atoms were refined anisotropically, hydrogen atom positions were derived from geometrical reasons apart from methyl-H that were located from Fourier maps using HFIX 137 from SHELX and then refined at idealized positions riding on the carbon atoms with isotropic displacement parameters $\mathrm{U}_{\text {iso }}(\mathrm{H})=1.2 \mathrm{U}_{\text {eq }}(\mathrm{C})$ or $1.5 \mathrm{U}_{\text {eq }}\left(-\mathrm{CH}_{3}\right)$ and $\mathrm{C}-\mathrm{H}$ 0.95-1.00 $\AA$. All $\mathrm{CH}_{3}$ hydrogen atoms were allowed to rotate but not to tip.

The two $\mathrm{H}(\mathrm{O})$ positions of the $\mathrm{dmgH}$ ligand in $\mathbf{3}$ could not be located due to disorder of the OH-groups resulting in equal $\mathrm{N}-\mathrm{O}$ distances for all 4 moieties. However, the existence of these $\mathrm{H}$ atoms is confirmed by mass spectrometry and IR spectra. 
The data sets suffer from rather bad crystal quality, especially of $\mathbf{3}$ which showed severe disorder of solvent region that could neither be identified nor modelled. Moreover, during anisotropic refinement some atoms went n.p.d., so finally only isotropic refinement was done. As the nature of the solvent for 3 is not clear, the sum formula as well as the derived parameters are not correct and we refrain from presenting further refinement results and extended geometric parameters.

1: $\left(\mathrm{C}_{55} \mathrm{H}_{55} \mathrm{FeN}_{9}\right)\left(\mathrm{PF}_{6}\right)_{2}, \mathrm{CHCl}_{3},\left(\mathrm{CH}_{3}\right)_{2} \mathrm{CO} ; \mathrm{M}_{\mathrm{r}}=1365.3$, red crystal, size 0.39 x $0.27 \times 0.22 \mathrm{~mm}^{3}$, monoclinic space group $\boldsymbol{C} c$ with $Z=4, \mathrm{a}=14.638(2), \mathrm{b}=17.080(3), \mathrm{c}=24.232(4) \AA, \beta=95.781(4)^{\circ}$, $\mathrm{V}=6027.7(16) \AA^{3} ; \mathrm{D}_{\mathrm{c}}=1.504 \mathrm{~g} / \mathrm{m}^{3}, \mu=0.523 \mathrm{~mm}^{-1}, \mathrm{~F}(000)=2808$. Refinement converged at $R I=0.078[I>2 \sigma(I)], \mathrm{w} R 2=0.202\left[\right.$ all data] and $\mathrm{S}=1.02 ; \min . / \max . \Delta \mathrm{F}-0.44 / 1.25 \mathrm{e} / \AA^{3}$ near $\mathrm{Fe}$ position.

2: $\left(\mathrm{C}_{56} \mathrm{H}_{58} \mathrm{FeN}_{9}\right)\left(\mathrm{PF}_{6}\right)_{3}, 2\left(\mathrm{CH}_{3}\right)_{2} \mathrm{CO} ; \mathrm{M}_{\mathrm{r}}=1464.0$, black crystal, size 0.19 x 0.17 x $0.15 \mathrm{~mm}^{3}$, orthorhombic space group Pna2 1 with $Z=4, a=25.0554(8), b=22.0915(6), c=12.0591(4) \AA$, $\mathrm{V}=6674.8(4) \AA^{3}, \mathrm{D}_{\mathrm{c}}=1.457 \mathrm{~g} / \mathrm{m}^{3}, \mu=3.379 \mathrm{~mm}^{-1}, \mathrm{~F}(000)=3016$. Refinement converged at $R I=0.0626[I>2 \sigma(I)], \mathrm{w} R 2=0.1740[$ all data $]$ and $\mathrm{S}=1.03 ; \min . / \max . \Delta \mathrm{F}-0.61 / 0.701 \mathrm{e} / \AA^{-3}$.

3: $\left(\mathrm{C}_{63} \mathrm{H}_{67} \mathrm{ClCoFeN}_{13} \mathrm{O}_{4}\right)\left(\mathrm{PF}_{6}\right)_{2}, 3 \mathrm{CHCl}_{3},\left(\mathrm{CH}_{3}\right)_{2} \mathrm{CO}$, Solv; $\mathrm{M}_{\mathrm{r}}=1926.6$, red crystal, size $0.47 \times 0.39 \mathrm{x}$ $0.22 \mathrm{~mm}^{3}$, orthorhombic space group $\boldsymbol{P} 2_{1} 2_{1} 2_{1}$ with $Z=4, \mathrm{a}=14.7034(15), \mathrm{b}=23.301(2), \mathrm{c}=25.772(3)$ $\AA, \mathrm{V}=8829.6(16) \AA^{3}$.

Crystallographic data for the structures $\mathbf{1}$ (excluding structure factors) and $\mathbf{2}$ have been deposited at the Cambridge Crystallographic Data Centre and are assigned to the deposition number CCDC-1547931 for compound 1 and CCDC-1852327 for compound 2. Copies of available material can be obtained free of charge via www.ccdc.cam.ac.uk.

EXAFS and XANES measurements of $\mathbf{3}$ were performed at beamline P65 at DESY -PETRAIII (Deutsches Elektronen-Synchrotron, Hamburg, Germany). A Si(111) double crystal monochromator was used for the measurements at the Fe K-edge $(7.112 \mathrm{keV})$ and the Co K-edge (7.709 keV). Energy calibration was performed with an iron foil and a cobalt foil respectively. The experiments were carried out under ambient conditions. The solid sample was diluted in cellulose as matrix and pressed into a pellet. The spectra were recorded in transmission mode with ionisation chambers filled with nitrogen. In both cases several spectra were collected and merged to obtain a better signal to noise ratio.

EXAFS and XANES measurements of $\mathbf{1}$ in combination with spectro-electrochemistry were performed at beamline BM25A at the European Synchrotron Radiation Facility (ESRF, Grenoble, France). A $\mathrm{Si}(111)$ double crystal monochromator was used for the measurements at the Fe K-edge $(7.112 \mathrm{keV})$ and again energy calibration was performed with an iron foil. The measurements of the solution (see below) were performed in specially designed spectro-electrochemistry cell, which will be described elsewhere. A gold gauze was employed as working electrode for bulk electrolysis with a gold wire counter electrode. As reference electrode Ag/0.01 M AgNO3, $0.1 \mathrm{M}\left[(\mathrm{n}-\mathrm{Bu})_{4} \mathrm{~N}\right] \mathrm{PF}_{6}$ in $\mathrm{MeCN}$ was used. The spectra were recorded in fluorescence mode using a 13-element germanium detector.

HERFD-XANES and VtC-XES measurements were carried out at beamline ID26 of the European Synchrotron Radiation Facility ESRF (Grenoble, France). For the measurements two u35 undulators were used. The incident X-ray beam had a flux of approximately $2 \cdot 10^{13}$ photons $\cdot \mathrm{s}^{-1}$ on the sample position. All measurements were conducted at $50 \mathrm{~K}$ using a He cryostat under vacuum conditions. Measurements were conducted with a Johann type X-ray emission spectrometer in the horizontal plane, where the sample, crystal analyzers and photon detector (avalanche photodiode) were arranged in a vertical Rowland geometry. Calibration of the emission spectrometer was performed using the elastic scattering line. The incident energy was selected using the $<111>$ reflection from a double Si crystal monochromator. The HERFD-XANES spectra at the Fe K edge were obtained by recording the intensity of the $\mathrm{Fe} \mathrm{K} \beta_{1,3}$ emission line as a function of the incident energy. The emission energy was selected using the $\langle 620\rangle$ reflection of five spherically bent Ge crystal analyzers (with $\mathrm{R}=1 \mathrm{~m}$ ) aligned at $80^{\circ}$ 
Bragg angle. The total fluorescence yield (TFY) was monitored by a photodiode installed at about $90^{\circ}$ scattering angle and at $45^{\circ}$ to the sample surface. During the XANES scans, the undulators were kept at a fixed gap and only the monochromator angle was changed. Each HERFD-XANES measurement was carried out in 100 seconds, one spectrum per point of the homogeneous sample, 10 spectra were averaged. To exclude radiation damage, 10 fast measurements with a scan time of 10 seconds were carried out. Within these time frames, no radiation damage could be detected (no decrease / increase / shift for all observed pre-edge / near-edge / white-line features).

For the VtC XES data collection, an incident energy of $7.2 \mathrm{keV}$ was chosen. VtC-XES energy scans were carried out in the range from $7065-7140 \mathrm{eV}$. To observe reasonable data, 20 spectra (100 seconds per scan) were recorded, utilizing a different sample spot for each scan.

THEORETICAL CALCULATIONS. All calculations presented here were performed with the ORCA package (version 4.0.1) ${ }^{[45]}$ Unconstrained geometry optimizations were conducted with the PBEh-3c method of the Grimme group. ${ }^{[46]}$ Minima structures were confirmed by numerical frequency calculations and the absence of negative frequencies.

TD DFT ${ }^{[47]}$ XANES and DFT VtC-XES calculations were accomplished using a modified TPSSh functional, with an adjusted Hartee Fock exchange ${ }^{[48]}$ of $12.5 \%$ in conjunction with the RIJCOSX approximation and the def2-TZVP ${ }^{[49]}$ basis set, combined with the def2-TZVP/J ${ }^{[50]}$ auxiliary basis set (with a special integration accuracy of 5) on all atoms except Fe, for which the expanded CP(PPP) basis set $^{[51]}$ (with a special integration accuracy of 7) was used. Correction for dispersion interaction was included via Becke-Johnson damping scheme (D3BJ). ${ }^{[52]}$

TD-DFT XANES transitions were broadened by a $1.5 \mathrm{eV}$ Gaussian (fwhm) and DFT VtC-XES transitions by a $2.5 \mathrm{eV}$ Gaussian (fwhm). Calculated TD-DFT XANES spectra were shifted by $151.5 \mathrm{eV}$ and DFT VtC-XES spectra were shifted by $149.4 \mathrm{eV}$. All calculated spectra were normalized on the number of Fe atoms per complex. Kohn Sham Orbitals were visualized with the IboView program (version 20150427)..$^{[53]}$

HOMO-LUMO gaps and MO levels were calculated using the TPSSh functional in conjunction with the def2-TZVPP basis set using very tight SCF convergence criteria (energy change of $1.010^{-9} \mathrm{au}$ ). Dispersion correction has been performed via Becke-Johnson damping scheme. Solvation by acetonitrile is covered by the SMD solvation model. ${ }^{[54]}$

Femtosecond Transient Absorption Spectroscopy. The femtosecond laser setup used for transient absorption spectroscopy has been previously described. ${ }^{[55]}$ The excitation beam was depolarized and set to $400 \mathrm{~nm}$. For these optical measurements, the time-dependent signals were analyzed through SVD decomposition, with a variable Gaussian instrument response function fitted to $120 \mathrm{fs}$ fwhm.

UV-Vis Spectroscopy. For all measurements, spectroscopy grade solvents from VWR and Sigma Aldrich were used. All measured solutions had a concentration of $10^{-5} \mathrm{~mol} / \mathrm{L}$. The absorption spectra were recorded with a PerkinElmer Lambda 45 double beam UV spectrophotometer using Quartz cuvettes by Hellma with a path length of $1 \mathrm{~cm}$.

Electrochemistry. Cyclic and square-wave voltammograms at room temperature were performed with the PAR101 potentiostat from Metrohm or the Compactstat from Ivium in MeCN/0.1 M [(n-Bu $\left.)_{4} \mathrm{~N}\right] \mathrm{PF}_{6}$ $\left(c_{\text {analyt }}=0.001 \mathrm{~mol} / \mathrm{L}\right)$ with the following three-electrode arrangement: $\mathrm{Pt}$ working electrode $(1 \mathrm{~mm}$ diameter) or glassy carbon working electrode (2 mm diameter), Ag/0.01 M AgNO3, $0.1 \mathrm{M}$ [(n$\left.\mathrm{Bu})_{4} \mathrm{~N}\right] \mathrm{PF}_{6}$ in $\mathrm{MeCN}$ as reference and $\mathrm{Pt}$ wire counter electrode. Ferrocene was added as internal standard after the measurements, and all potentials are referenced relative to the $\mathrm{Fc} / \mathrm{Fc}^{+}$couple. The cyclic and square-wave voltammograms were analyzed with the software NOVA version 1.10 .5 from Metrohm and IviumSoft 2.794, respectively. The interpretation of the voltammetric response was performed on the basis of the diagnostic criteria proposed by Nicholson ${ }^{[56]}$ and the Randles-Sevcik equitation. ${ }^{[57]}$ 
Spectroelectrochemical and coulometric experiments at room temperature were performed in an optically transparent electrochemical cell $\left(\mathrm{d}=4 \mathrm{~mm}, \mathrm{MeCN} / 0.1 \mathrm{M}\left[(\mathrm{n}-\mathrm{Bu})_{4} \mathrm{~N}\right] \mathrm{PF}_{6}\right.$ as supporting electrolyte) with a Pt gauze working electrode. During oxidations/reductions, spectral changes were recorded on a Varian Cary 50 spectrophotometer in the range 200-1100 nm. All measurements were carried out under argon atmosphere, with absolute and deoxygenated acetonitrile. Note: Diagnostic criteria slightly deviate from perfect reversible behavior, because solution resistances are not completely compensated by the electrochemical instrumentation.

\section{Acknowledgements}

KZ thanks the financial support from the Swedish research council VR staring grant (No. 2017-05337) and Independent Research Fund Denmark Sapere Aude starting grant (No. 7026-00037A) SEC acknowledges funding from the Helmoltz Recognition Award. The ELI-ALPS project (GINOP-2.3.615-2015-00001) is financed by the European Union and co-financed by the European Regional Development Fund. This research used resources of the Center for Nanoscale Materials, U.S. Department of Energy (DOE) Office of Science User Facilities operated for the DOE Office of Science by Argonne National Laboratory under Contract No. DE-AC02-06CH11357. P.Z. thanks the Fonds der Chemischen Industrie for a Kekulé grant. The ESRF (beamline ID26: Pieter Glatzel, Rafal Baran, beamline 25A: Germán Castro, Aida Serrano) and DESY - PETRAIII (beamline P65, Edmund Welter) is acknowledged for a provision of beamtime. Generous grants of computer time at the Paderborn Center for Parallel Computing PC2 is gratefully acknowledged. The German ministry Bundesministerium für Bildung und Forschung (BMBF) is kindly acknowledged for funding in the frame of the German-Swedish project SusChEmX (F.-Kz. 05K14PP1).

[1] a) E. Amouyal, Sol. Energ. Mat. Sol. Cells 1995, 38(1-4), 249-276; b) K. Kalyanasundaram, J. Kiwi, M. Grätzel, Helv. Chim. Acta 1978, 61(7), 2720-2730;

[2] D. Miller, G. McLendon, Inorg. Chem. 1981, 20(3), 950-953.

[3] a) L. L. Tinker, S. Bernhard, Inorg. Chem. 2009, 48(22), 10507-10511; b) F. Gärtner, S. Denurra, S. Losse, A. Neubauer, A. Boddien, A. Gopinathan, A. Spannenberg, H. Junge, S. Lochbrunner, M. Blug, S. Hoch, J. Busse, S. Gladiali, M. Beller, Chem. Eur. J. 2012, 18(11), 3220-3225; c) J. I. Goldsmith, W. R. Hudson, M. S. Lowry, T. H. Anderson, S. Bernhard, J. Am. Chem. Soc. 2005, 127(20), 7502-7510; d) L. L. Tinker, N. D. McDaniel, P. N. Curtin, C. K. Smith, M. J. Ireland, S. Bernhard, Chem. Eur. J. 2007, 13(31), 8726-8732;

[4] K. Sakai, H. Ozawa, Coord. Chem. Rev. 2007, 251(21-24), 2753-2766.

[5] L. L. Tinker, N. D. McDaniel, S. Bernhard, J. Mater. Chem. 2009, 19(21), 3328-3337.

[6] A. Panagiotopoulos, K. Ladomenou, D. Sun, V. Artero, A. G. Coutsolelos, Dalton transactions (Cambridge, England : 2003) 2016, 45(15), 6732-6738.

[7] a) S.-P. Luo, E. Mejía, A. Friedrich, A. Pazidis, H. Junge, A.-E. Surkus, R. Jackstell, S. Denurra, S. Gladiali, S. Lochbrunner, M. Beller, Angew. Chem. Int. Ed. Engl. 2013, 52(1), 419-423; b) F. Gärtner, A. Boddien, E. Barsch, K. Fumino, S. Losse, H. Junge, D. Hollmann, A. Brückner, R. Ludwig, M. Beller, Chem. Eur. J. 2011, 17(23), 6425-6436; c) R. Lomoth, S. Ott, Dalton Trans. 2009(45), 9952-9959;

[8] T. C. B. Harlang, Y. Liu, O. Gordivska, L. A. Fredin, C. S. Ponseca, P. Huang, P. Chábera, K. S. Kjaer, H. Mateos, J. Uhlig, R. Lomoth, R. Wallenberg, S. Styring, P. Persson, V. Sundström, K. Wärnmark, Nat. Chem. 2015, 7(11), 883-889.

[9] Y. Liu, P. Persson, V. Sundström, K. Wärnmark, Acc. Chem. Res. 2016, 49(8), 1477-1485.

[10] P. Chabera, Y. Liu, O. Prakash, E. Thyrhaug, A. E. Nahhas, A. Honarfar, S. Essen, L. A. Fredin, T. C. B. Harlang, K. S. Kjaer, K. Handrup, F. Ericson, H. Tatsuno, K. Morgan, J. Schnadt, L. Haggstrom, T. Ericsson, A. Sobkowiak, S. Lidin, P. Huang, S. Styring, J. Uhlig, J. Bendix, R. Lomoth, V. Sundstrom, P. Persson, K. Warnmark, Nature 2017, 543(7647), 695-699. 
[11] P. Chábera, K. S. Kjaer, O. Prakash, A. Honarfar, Y. Liu, L. A. Fredin, T. C. B. Harlang, S. Lidin, J. Uhlig, V. Sundström, R. Lomoth, P. Persson, K. Wärnmark, J. Phys. Chem. Lett. 2018, 9(3), 459463.

[12] K. S. Kjær, K. Kunnus, T. C. B. Harlang, van Driel, Tim B, K. Ledbetter, R. W. Hartsock, M. E. Reinhard, S. Koroidov, L. Li, M. G. Laursen, E. Biasin, F. B. Hansen, P. Vester, M. Christensen, K. Haldrup, M. M. Nielsen, P. Chabera, Y. Liu, H. Tatsuno, C. Timm, J. Uhlig, V. Sundstöm, Z. Németh, D. S. Szemes, É. Bajnóczi, G. Vankó, R. Alonso-Mori, J. M. Glownia, S. Nelson, M. Sikorski, D. Sokaras, H. T. Lemke, S. E. Canton, K. Wärnmark, P. Persson, A. A. Cordones, K. J. Gaffney, Phys. Chem. Chem. Phys. 2018, 20(6), 4238-4249.

[13] P. Zimmer, L. Burkhardt, A. Friedrich, J. Steube, A. Neuba, R. Schepper, P. Müller, U. Flörke, M. Huber, S. Lochbrunner, M. Bauer, Inorganic chemistry 2018, 57(1), 360-373.

[14] a) S. G. Shepard, S. M. Fatur, A. K. Rappé, N. H. Damrauer, J. Am. Chem. Soc. 2016; b) I. M. Dixon, G. Boissard, H. Whyte, F. Alary, J.-L. Heully, Inorg. Chem. 2016, 55(11), 5089-5091; c) L. A. Fredin, M. Pápai, E. Rozsályi, G. Vankó, K. Wärnmark, V. Sundström, P. Persson, J. Phys. Chem. Lett. 2014, 2066-2071; d) A. K. C. Mengel, C. Bissinger, M. Dorn, O. Back, C. Förster, K. Heinze, Chemistry (Weinheim an der Bergstrasse, Germany) 2017, 23(33), 7920-7931;

[15] L. Liu, T. Duchanois, T. Etienne, A. Monari, M. Beley, X. Assfeld, S. Haacke, P. C. Gros, Phys. Chem. Chem. Phys. 2016, 18(18), 12550-12556.

[16] T. Duchanois, T. Etienne, C. Cebrián, L. Liu, A. Monari, M. Beley, X. Assfeld, S. Haacke, P. C. Gros, Eur. J. Inorg. Chem. 2015, 2015(14), 2469-2477.

[17] Y. Liu, T. Harlang, S. E. Canton, P. Chábera, K. Suárez-Alcántara, A. Fleckhaus, D. A. Vithanage, E. Göransson, A. Corani, R. Lomoth, V. Sundström, K. Wärnmark, Chem. Commun. (Camb.) 2013, 49(57), 6412-6414.

[18] T. Duchanois, T. Etienne, M. Beley, X. Assfeld, E. A. Perpète, A. Monari, P. C. Gros, Eur. J. Inorg. Chem. 2014, 2014(23), 3747-3753.

[19] P. Zimmer, P. Müller, L. Burkhardt, R. Schepper, A. Neuba, J. Steube, F. Dietrich, U. Flörke, S. Mangold, M. Gerhards, M. Bauer, Eur. J. Inorg. Chem. 2017, 2017(11), 1504-1509.

[20] J. L. Dempsey, B. S. Brunschwig, J. R. Winkler, H. B. Gray, Acc. Chem. Res. 2009, 42(12), 19952004.

[21] a) E. C. Constable, Cargill Thompson, Alexander M.W, N. Armaroli, V. Balzani, M. Maestri, Polyhedron 1992, 11(20), 2707-2709; b) H. Lv, J. A. Rudd, P. F. Zhuk, J. Y. Lee, E. C. Constable, C. E. Housecroft, C. L. Hill, D. G. Musaev, Y. V. Geletii, RSC Adv 2013, 3(43), 20647-20654;

[22] E. C. Constable, Thompson, Alexander M. W. Cargill, J. Chem. Soc, Dalton Trans. 1994, 32(9), 1409-1418.

[23] E. C. Constable, C. E. Housecroft, M. Neuburger, D. Phillips, P. R. Raithby, E. Schofield, E. Sparr, D. A. Tocher, M. Zehnder, Y. Zimmermann, J. Chem. Soc, Dalton Trans. 2000(13), 2219-2228.

[24] A. Jacques, O. Schott, K. Robeyns, G. S. Hanan, B. Elias, Eur. J. Inorg. Chem. 2016, 2016(12), 1779-1783.

[25] C. L. Bird, A. T. Kuhn, Chem. Soc. Rev. 1981, 10(1), 49-82.

[26] a) A. Fihri, V. Artero, M. Razavet, C. Baffert, W. Leibl, M. Fontecave, Angew. Chem. 2008, 120(3), 574-577; b) W. T. Eckenhoff, W. R. McNamara, P. Du, R. Eisenberg, Biochimica et biophysica acta 2013, 1827(8-9), 958-973;

[27] A. A. Danopoulos, N. Tsoureas, J. A. Wright, M. E. Light, Organometallics 2004, 23(2), $166-168$.

[28] G. N. Schrauzer, G. W. Parshall, E. R. Wonchoba in Inorganic syntheses. Volume 11; (Ed. W. L. Jolly), McGraw-Hill, New York, 1968, pp. 61-70.

[29] S. Geremia, R. Dreos, L. Randaccio, G. Tauzher, L. Antolini, Inorg. Chim. Acta 1994, 216(1-2), 125-129.

[30] P. Glatzel, U. Bergmann, Coord. Chem. Rev. 2005, 249(1-2), 65-95.

[31] M. Bauer, Phys. Chem. Chem. Phys. 2014, 16(27), 13827-13837. 
[32] P. E. Rutherford, D. A. Thornton, Spectrochimica Acta Part A: Molecular Spectroscopy 1979, 35(6), 711-714.

[33] C. Lentz, O. Schott, T. Auvray, G. Hanan, B. Elias, Inorg. Chem. 2017, 56(18), 10875-10881.

[34] W. Liptay, Angew. Chem. 1969, 81(6), 195-206.

[35] A. Kahnt, K. Peuntinger, C. Dammann, T. Drewello, R. Hermann, S. Naumov, B. Abel, D. M. Guldi, The journal of physical chemistry. A 2014, 118(25), 4382-4391.

[36] E. Ngameni, J. Ngoune, A. Nassi, M.M. Belombe, R. Roux, Electrochimica Acta 1996, 41(16), 2571-2577.

[37] N. H. Damrauer, J. K. McCusker, J. Phys. Chem. A 1999, 103(42), 8440-8446.

[38] F. Ericson, A. Honarfar, O. Prakash, H. Tatsuno, L. A. Fredin, K. Handrup, P. Chabera, O. Gordivska, K. S. Kjær, Y. Liu, J. Schnadt, K. Wärnmark, V. Sundström, P. Persson, J. Uhlig, Chem. Phys. Lett. 2017, 683, 559-566.

[39] C. Reichardt, Solvents and solvent effects in organic chemistry; WILEY-VCH, Weinheim, 2003.

[40] C. R. Hecker, A. K. I. Gushurst, D. R. McMillin, Inorg. Chem. 1991, 30(3), 538-541.

[41] K. S. Kjær, W. Zhang, R. Alonso-Mori, U. Bergmann, M. Chollet, R. G. Hadt, R. W. Hartsock, T. Harlang, T. Kroll, K. Kubiček, H. T. Lemke, H. W. Liang, Y. Liu, M. M. Nielsen, J. S. Robinson, E. I. Solomon, D. Sokaras, van Driel, Tim B, T.-C. Weng, D. Zhu, P. Persson, K. Wärnmark, V. Sundström, K. J. Gaffney, Structural dynamics (Melville, N.Y.) 2017, 4(4), 44030.

[42] J. Wang, G. Hanan, Synlett 2005, 2005(08), 1251-1254.

[43] A. A. Danopoulos, Tulloch, Arran A. D, S. Winston, G. Eastham, M. B. Hursthouse, Dalton transactions (Cambridge, England : 2003) 2003(5), 1009-1015.

[44] G. M. Sheldrick, Acta Crystallogr, Sect. A: Found. Crystallogr. 2008, 64(Pt 1), 112-122.

[45] F. Neese, Wiley Interdiscip. Rev.-Comput. Mol. Sci. 2018, 8(1), e1327.

[46] J. Hostaš, J. Řezáč, J. Chem. Theory Comput. 2017, 13(8), 3575-3585.

[47] a) S. DeBeer George, T. Petrenko, F. Neese, Inorg. Chim. Acta 2008, 361(4), 965-972; b) S. DeBeer George, T. Petrenko, F. Neese, J. Phys. Chem. A 2008, 112(50), 12936-12943;

[48] M. Roemelt, M. A. Beckwith, C. Duboc, M.-N. Collomb, F. Neese, S. DeBeer, Inorg. Chem. 2012, 51(1), 680-687.

[49] F. Weigend, R. Ahlrichs, Phys. Chem. Chem. Phys. 2005, 7(18), 3297-3305.

[50] F. Weigend, Phys. Chem. Chem. Phys. 2006, 8(9), 1057-1065.

[51] F. Neese, Inorg. Chim. Acta 2002, 337, 181-192.

[52] a) S. Grimme, S. Ehrlich, L. Goerigk, J. Comp. Chem. 2011, 32(7), 1456-1465; b) S. Grimme, J. Antony, S. Ehrlich, H. Krieg, The Journal of chemical physics 2010, 132(15), 154104;

[53] G. Knizia, iboview; http://www.iboview.org.

[54] A. V. Marenich, C. J. Cramer, D. G. Truhlar, J. Phys. Chem. B 2009, 113(18), 6378-6396.

[55] J. J. Burdett, D. Gosztola, C. J. Bardeen, The Journal of chemical physics 2011, 135(21), 214508.

[56] a) R. S. Nicholson, I. Shain, Anal. Chem. 1964, 36(4), 706-723; b) J. Heinze, Angew. Chem. 1984, 96(11), 823-840;

[57] a) J. E. B. Randles, Trans. Faraday Soc. 1948, 44, 327; b) F. Scholz, Electroanalytical methods: Guide to experiments and applications; Springer, Berlin, 2010; 